\title{
The intensification of thermal extremes in west Africa
}

Ringard, J. , Dieppois, B. , Rome, S. , Diedhiou, A. , Pellarin, T. , Konaré, A. , Diawara, A. , Konaté, D. , Dje, B.K. , Katiellou, G.L. , Seidou Sanda, I. , Hassane, B. , Vischel, T. , Garuma, G.F. , Mengistu, G. , Camara, M. , Diongue, A. , Gaye, A.T. and Descroix, L.

Author post-print (accepted) deposited by Coventry University's Repository

Original citation \& hyperlink:

Ringard, J. , Dieppois, B. , Rome, S. , Diedhiou, A. , Pellarin, T. , Konaré, A. , Diawara, A. , Konaté, D. , Dje, B.K. , Katiellou, G.L. , Seidou Sanda, I. , Hassane, B. , Vischel, T. , Garuma, G.F. , Mengistu, G. , Camara, M. , Diongue, A. , Gaye, A.T. and Descroix, L. (2015) The intensification of thermal extremes in west Africa. Global and Planetary Change, volume 39 : 66-77

http://dx.doi.org/10.1016/i.gloplacha.2015.12.009

DOI 10.1016/j.gloplacha.2015.12.009

ISSN 0921-8181

Publisher: Elsevier

NOTICE: this is the author's version of a work that was accepted for publication in Global and Planetary Change. Changes resulting from the publishing process, such as peer review, editing, corrections, structural formatting, and other quality control mechanisms may not be reflected in this document. Changes may have been made to this work since it was submitted for publication. A definitive version was subsequently published in Global and Planetary Change, [VOL 39, (2015)] DOI: 10.1016/j.gloplacha.2015.12.009

(C) 2015, Elsevier. Licensed under the Creative Commons AttributionNonCommercial-NoDerivatives 4.0 International http://creativecommons.org/licenses/by-nc-nd/4.0/

Copyright $(\subset$ and Moral Rights are retained by the author(s) and/ or other copyright owners. A copy can be downloaded for personal non-commercial research or study, without prior permission or charge. This item cannot be reproduced or quoted extensively from without first obtaining permission in writing from the copyright holder(s). The content must not be changed in any way or sold commercially in any format or medium without the formal permission of the copyright holders. 
This document is the author's post-print version, incorporating any revisions agreed during the peer-review process. Some differences between the published version and this version may remain and you are advised to consult the published version if you wish to cite from it. 


\section{Accepted Manuscript}

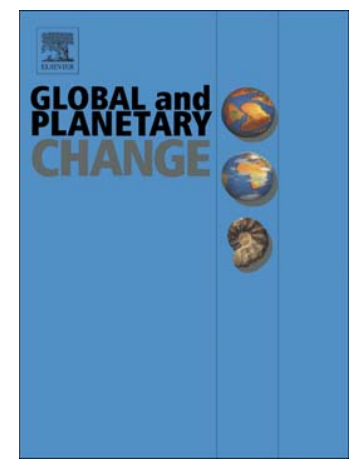

PII:

DOI:

Reference:

S0921-8181(15)30162-4

J. Ringard, B. Dieppois, S. Rome, A. Diedhiou, T. Pellarin, A. Konaré, A. Diawara, D. Konaté, B.K. Dje, G.L. Katiellou, I. Seidou Sanda, B. Hassane, T. Vischel, G.F. Garuma, G. Mengistu, M. Camara, A. Diongue, A.T. Gaye, L. Descroix

To appear in: Global and Planetary Change

Received date: 10 December 2014

Revised date: $\quad 14$ November 2015

Accepted date: 15 December 2015

Please cite this article as: Ringard, J., Dieppois, B., Rome, S., Diedhiou, A., Pellarin, T., Konaré, A., Diawara, A., Konaté, D., Dje, B.K., Katiellou, G.L., Seidou Sanda, I., Hassane, B., Vischel, T., Garuma, G.F., Mengistu, G., Camara, M., Diongue, A., Gaye, A.T., Descroix, L., The intensification of thermal extremes in west Africa, Global and Planetary Change (2015), doi: 10.1016/j.gloplacha.2015.12.009

This is a PDF file of an unedited manuscript that has been accepted for publication. As a service to our customers we are providing this early version of the manuscript. The manuscript will undergo copyediting, typesetting, and review of the resulting proof before it is published in its final form. Please note that during the production process errors may be discovered which could affect the content, and all legal disclaimers that apply to the journal pertain. 


\section{THE INTENSIFICATION OF THERMAL EXTREMES \\ IN WEST AFRICA}

Ringard J. ${ }^{(1)}$, Dieppois B. ${ }^{(2,3,4)}$, Rome ${ }^{(5)}$, Diedhiou A. ${ }^{(6)}$, Pellarin T. ${ }^{(7)}$, Konaré A. ${ }^{(8)}$, Diawara A. ${ }^{(8)}$, Konaté D. ${ }^{(9)}$, Dje B. K. ${ }^{(9)}$, Katiellou G.L. ${ }^{(10)}$, Seidou Sanda I. ${ }^{(11)}$, Hassane B. ${ }^{(12)}$, Vischel T. ${ }^{(5)}$, Garuma G.F. ${ }^{(13)}$, Mengistu G. ${ }^{(13)}$, Camara M. ${ }^{(14)}$, Diongue A. ${ }^{(15)}$, Gaye A.T. ${ }^{(16)}$, Descroix L. ${ }^{(17)}$

(1) Université de Guyane, IRD, UMR ESPACE-DEV, F97300 Cayenne, Guyane

(2) Centre for Agroecology, Water and Resilience, Coventry University, UK.

(3) African Climate \& Development Initiative, University of Cape Town, RSA.

(4) Department of Oceanography, MARE Institute, University of Cape Town, RSA

(5) Université Grenoble Alpes, LTHE UMR 5564, BP 53, 38041 Grenoble, France

(6) IRD, LTHE UMR 5564, 38041 Grenoble, France [arona.diedhiou@ird.fr]

(7) CNRS, LTHE UMR 5564, 38041 Grenoble, France.

(8) Université Félix Houphouët Boigny, UFR SSMT / LAPA-MF, Abidjan, Ivory Coast

(9) SODEXAM, Meteorological Dept., 15 BP 990 Abidjan, Ivory Coast

(10) Niger Meteorological Office, BP. 218 Niamey, Niger

(11) Centre Régional AGRHYMET/CILSS; BP 11011 Niamey, Niger

(12) University Abdou Moumouni, Niamey, Niger

(13) Addis Ababa Univ., Physics Department, Arat Kilo Campus, Addis Ababa, Ethiopia.

(14) Université AssaneSeck of Ziguinchor, BP 523, Ziguinchor, Senegal

(15) ANACIM, Météorological Dept., BP 8257 Dakar-Yoff, Dakar, Senegal

(16) Université Cheikh Anta Diop of Dakar, ESP / LPAOSF, Dakar, Senegal

(17) Muséum National d'Histoire Naturelle, UMR 208 PALOC, Paris, France 


\section{Abstract}

This study aims in filling the gap in understanding the relationship between trend and extreme in diurnal and nocturnal temperatures (Tx and Tn) over the Gulf of Guinea area and the Sahel. Time-evolution and trend of $\mathrm{Tx}$ and $\mathrm{Tn}$ anomalies, extreme temperatures and the timeevolution and trend of heat waves are examined using regional and station-based indices over the 1900-2012 and 1950-2012 periods respectively. In investigating extreme temperature anomalies and heat waves, a percentile method is used (T90p). At the regional and local scales, rising trends in Tx and Tn anomalies, which appear more pronounced over the past 60 years, are identified over the two regions. The trends are characterized by an intensification of: i) nocturnal/Tn warming over the second half of the $20^{\text {th }}$ century; and ii) diurnal/Tx warming over the post-1980s. This is the same scheme with extreme warm days and warm nights. Finally annual number of diurnal and nocturnal heat waves has increase over the Gulf of Guinea coastal regions over the second half of the $20^{\text {th }}$ century, and even more substantially over the post-1980s period. Although this trend in extreme warm days and nights is always overestimated in the simulations, from the Coupled Model Intercomparison Project Phase 5 (CMIP5), those models display rising trends whatever the scenario, which are likely to be more and more pronounced over the two regions in the next 50 years.

Keywords: West Africa, Trend, Daily temperature anomalies, Extreme temperature, Heat Waves, CMIP5 


\section{Introduction}

Post-1970s warming temperatures over West Africa, and in particular over the Sahel, have been reported somewhat faster than at the global scales (ECOWAS-SWAC/OECD/CILS, 2008; Hulme, 2001): Saharo-Sahelian, Sahelian and Sudano-Sahelian temperatures have risen by between $0.2^{\circ} \mathrm{C}$ and $0.8^{\circ} \mathrm{C}$. Current state-of-the-art CMIP5 coupled models (Taylor et al., 2012) are reasonably consistent in predicting warm conditions over West Africa, but there are large discrepancies in terms of intensity of changes (Stocker et al., 2013). According to the last report of the Intergovernmental Panel on Climate Change, land areas might warm by as much as $1.6^{\circ} \mathrm{C}$ by 2050 over the Sahara and semi-arid parts of southern Africa (Stocker et al., 2013).

At the global scale, Braganza et al. (2004), have reported a decrease in daily temperature range (i.e., maximal/diurnal minus minimal/nocturnal daily temperatures [Tx-Tn]), which is characterized by greater rises in minimal/nocturnal temperatures (Tn) than in maximal/diurnal temperatures (Tx). According to Stone and Weaver (2002), the observed decrease in daily temperature range could be the climate system's response to the increase in greenhouse-gas concentrations in the atmosphere. However, such a discrepancy in between the trend of Tx and Tn trend have never been studied over the West-African regions. In addition, as proposed at the global scale (e.g., Christensen et al., 2007; Pachauri and Reisinger, 2008; Stocker et al., 2013), warming temperatures is likely to contribute in increasing occurrences of extreme temperatures, as well as heat wave (HW) events. For instance, at the global scale, Meehl and Tebaldi (2004) noted that warming nocturnal temperatures is associated with an increase in the number of HWs.

HWs have been defined as a period of consecutive days where conditions are excessively hotter than normal at that time of the year. There is therefore no universal definition of heat waves, and many definition could apply depending on the study region (Meehl and Tebaldi, 
2004; Alexander et al., 2006; Donat et al., 2013). Since the Chicago HW of July 1995 and that of Western Europe in August 2003 - both followed by supernumerary rises in death rates such events have been extensively studied in the mid-latitudes of the Northern Hemisphere (e.g., Beniston and Diaz, 2004; Bessemoulin et al., 2004; Black et al., 2004; Trigo et al., 2005). Extreme heat events in the tropics have been much less studied, even though it also concerns the tropical areas, as shown by the extreme heat experienced in Niamey in April 2010 (daily Tx overtaking $44.5^{\circ} \mathrm{C}$ from 18 till 22 April). This event had significant effects on agriculture, hydrological processes and health of populations. HWs can indeed be accompanied by increased rates of atmospheric pollution. Air pollution is a major threat to population health, as it is the cause of a number of respiratory and cardiovascular diseases (World Health Organisation, 2002).

This study aims in filling the gap in understanding the relationship between trend and extreme in diurnal and nocturnal temperatures (Tx and Tn) over the Gulf of Guinea area $\left(4^{\circ}-10^{\circ} \mathrm{N}\right.$; $10^{\circ} \mathrm{W}-10^{\circ} \mathrm{E}$; cf. Figure 1) and the Sahel $\left(10^{\circ}-20^{\circ} \mathrm{N} ; 10^{\circ} \mathrm{W}-10^{\circ} \mathrm{E}\right.$; cf. Figure 1$)$. This study also helps to determine whether this relationship, which is here discussed through seasonal fluctuations, is different from that reported at the global scale. For instance, are the trend greater in Tn than in Tx, and are this associated with an increase of nocturnal HWs. In addition, potential definition of thermal extreme and HW indices will be discussed for the Gulf of Guinea coastal regions and the Sahel. Data and methods are described in Section 2. We then present the seasonal temperature fluctuations in the West African region, before to focus on two regions: the Gulf of Guinea (Abidjan) coastal regions and the Sahel (Niamey). In Section 3.1, time-evolution and trend of Tx and Tn anomalies during the $20^{\text {th }}$ century is investigated. In Section 3.2, we focus on the extreme values in the seasonal temperature anomalies through different indices, which allow to examine the time-evolution and trend of HWs. Finally, in Section 3.3, observed trends of extreme heat events are compared to those simulated by the global climate models from the CMIP5. 


\section{Data and methods}

\subsection{Data}

We use National Centers for Environmental Prediction / National Center for Atmospheric Research Reanalysis data (NCEP/NCAR-1; Kalnay et al., 1996), with a horizontal resolution of $2.5^{\circ} \times 2.5^{\circ}$, to represent the seasonal evolution of mean temperatures (at 2 metres above the ground) over West Africa between 1951 and 1980 (i.e., baseline period of seasonal temperature anomalies in Sections 3.1-3).

Tx and Tn trends are analysed at the regional and local scales. At the regional scale, the daily homogenised Berkeley Earth Surface Temperatures (BEST) observation data set has been used. Between 1900 and 2012, these data show daily Tx and Tn anomalies with a spatial resolution of $1^{\circ} \times 1^{\circ}$ (Rohde et al., 2013). These daily anomalies were calculated by subtracting for each day its monthly climatology (i.e., the monthly mean) with respect to the 1951-1980 base period. Gridded temperature anomalies from BEST are derived from, approximately, 39000 weather stations distributed around the world, which is five times more than other data sets (e.g., CRU/Hadley Centre, NCDC/NOAA and GISS/NASA). Despite this, density of observation network remains an intractable problem over the Sahara. A variety of treatments (e.g., filter, interpolation and merge) have been done on the raw data. The different steps are listed in Berkeley Earth website in http://berkeleyearth.org/about-data-set. At the local scale, daily Tx and Tn anomalies are examined in Abidjan and Niamey between 1950 and 2012. This data were provided by the Société D'EXportation et de dévelopement Aéroportuaire, Aéronautique et Météorologique (SODEXAM) of Abidjan Port-Bouët, and the Direction de la Météorologie Nationale (DMN) of Niger. These stations have been selected for their long temporal lengths (i.e., 60 years) without big gaps, but also for their quality. Several homogeneity tests, such as Pettitt, Mann-Whitney-Wilcoxon Buishand, Cumulative deviation, Worsley, has been applied. These tests show a significant break in 1983 for Niamey 
and 1986 for Abidjan (not shown), which were not associated with modifications of measurement conditions, such as gauge displacement, measurement instrument replacement, change in gauge exposure or environment (Rome et al., 2015).

Finally, simulations from five coupled models of the CMIP5 project, and an ensemble mean of 24 CMIP5 models (Taylor et al., 2012), have been used to be compared with observations (Table 1). The "one model, one vote" approach of Santer et al. (2009), i.e., the first realisation of each model, has been used. It ensures that each model has the same weight and that the results are due to "outlier" model or to stronger weight for given climate centre. Comparisons with observations have been done using "historical" runs. Between 1900 and 2005, these simulations provide a realistic representation of global climate variation due to anthropogenic and natural forcing (e.g., solar, volcanic, sulphates, aerosols and greenhouse gases, land use). Historical trends were then compared with those projected over the $21^{\text {st }}$ century under two Representative Concentration Pathway (RCP) scenarios: RCP 2.6 and RCP 8.5, i.e. the most optimistic and the most pessimistic emissions of well-mixed greenhouse gases (in W.m $\mathrm{m}^{-2}$ ).

\begin{tabular}{|c|c|c|c|}
\hline Models & $\begin{array}{c}\text { Resolution } \\
(\text { Lat } \times \text { Lon) }\end{array}$ & Institution & Country \\
\hline CMIP5 Mean & $2.5^{\circ} \times 2.5^{\circ}$ & & \\
\hline CNRM-CM5 & $1.4^{\circ} \times 1.4^{\circ}$ & $\begin{array}{c}\text { Centre national de Recherche Météorologique } \\
\text { (CNRM) / Centre Européen de Recherche et de } \\
\text { Formation Avancée en Calcul Scientifique } \\
\text { (CERFACS) }\end{array}$ & France \\
\hline $\begin{array}{l}\text { IPSL-CM5A- } \\
\text { LR }\end{array}$ & $\begin{array}{c}1.865^{\circ} \times \\
3.75^{\circ}\end{array}$ & Institut Pierre-Simon Laplace (IPSL) & France \\
\hline MPI-ESM-LR & $\begin{array}{c}1.865^{\circ} \times \\
1.875^{\circ}\end{array}$ & Max Planck Institut (MPI) & Germany \\
\hline HadGEM2-ES & $\begin{array}{l}1.25^{\circ} \times \\
1.875^{\circ}\end{array}$ & Met Office Hadley Center (MOHC) & $\begin{array}{l}\text { United } \\
\text { Kingdom }\end{array}$ \\
\hline CanESM2 & $\begin{array}{l}2.79^{\circ} \times \\
2.813^{\circ}\end{array}$ & $\begin{array}{c}\text { Canadian Centre for Climate modelling and } \\
\text { analysis (CCCma) }\end{array}$ & Canada \\
\hline
\end{tabular}

Table 1. Summarised information on CMIP5 models used in the study.

\subsection{Methods}


A set of statistical analyses has been designed to identify trends in temperatures at the regional (i.e., the regionalised temperature index for the Sahel and the Gulf of Guinea area) and local scales (i.e., Niamey and Abidjan stations). The daily Tx and Tn anomalies are calculated by subtracting for each day its monthly climatology with respect to the 1951-1980 base period. This reduces uncertainties associated with the absolute temperature (Rohde et al., 2013; Cowtan and Way, 2014), but also reduces the influences of seasonal fluctuations. Daily Tx and Tn anomalies are then averaged on a seasonal time-step (i.e., JFM, AMJ, JAS, SON).

To examine the time-evolution of extreme temperature anomalies and HWs, we used the $90^{\text {th }}$ percentile of daily Tx and Tn anomalies (Tx90p and Tn90p), with respect to the 1951-1980 base period, as threshold. The Tx90p and Tn90p have been widely used through international projects about the detection of extreme temperatures and HWs at the regional and global scales, e.g., IMFREX ("IMpact des changements anthropiques sur la FRéquence des phénomènes EXtrêmes de vent, de température et de précipitations"; Déqué, 2005)),

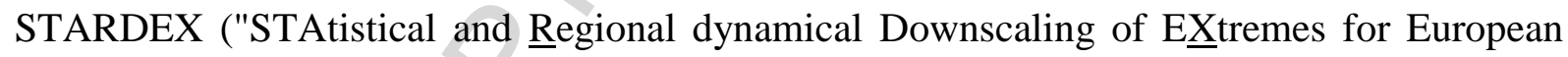
regions"; Goddess, 2005) and ClimdEX (Alexander et al., 2006; Donat et al., 2013). According to Zhang et al. (2005), great care is required to estimate the Tx90p and Tn90p to ensure that inhomogeneities are not introduced into the index time series at the boundaries of the base periods that are used to determine the thresholds (i.e., 1951-1980). A bootstrap procedure, which proposed to replicate the Tx90p and Tn90p calculations using a geometric block resampling over the base period, has therefore been used. Time-evolution of extreme temperature indices is then discussed for every significant Tx90p and Tn90p values, i.e., in the nonparametric bootstrap confidence intervals at $95 \%$, as determined from a normal distribution. Eight indices of extreme temperatures anomalies are derived from this procedure for each region: i) the seasonal percentage of days when Tx exceeds the $90^{\text {th }}$ percentile (i.e., Tx90p); ii) the seasonal percentage of nights warmer than the Tn90p; iii) the maximal duration of diurnal HWs, i.e., maximal consecutive days exceeding the Tx90p; iv) the 
maximal duration of nocturnal HWs, i.e., maximal consecutive nights exceeding the Tn90p; v) the mean duration of diurnal HWs; vi) the mean duration of nocturnal HWs; vii) the annual number of diurnal HWs, which is defined as annual count of spells with at least $n$ consecutive days when Tx anomalies exceed the Tx90p; viii) the annual number of nocturnal HWs, which is defined as annual count of spells with at least $n$ consecutive days when Tn anomalies exceed the Tn90p. However, the number of consecutive days $n$, which is required to define HWs, varies greatly in the literatures; it is very sensitive to the study region. At least 6 consecutive days was proposed at the global scale by the ClimDEX project (Alexander et al., 2006; Donat et al., 2013), but other studies also reduce that value to 3 (e.g., Perkins et al., 2012; Perkins and Alexander, 2013). In the present study, to discuss this choice with regards to the West African region, the annual number of diurnal and nocturnal HWs has been investigated for $3 \leq n \leq 8$ consecutive days.

Next, monotonic trends in time series were calculated using a modified Mann-Kendall trend test accounting for serial correlation (Hamed and Rao, 1998; Yue and Wang, 2004). To eliminate the effect of serial correlation, the effective sample size, which allows us to modify the Mann-Kendall $S$ statistic, has been estimated according to a theoretical relationship based on first-order auto-regressive model of each time series considered. The Sen's slopes associated with trend intensity are then calculated (Sen, 1968), while the statistical significance is assumed by the $p$-value (hereafter, at $p=0.05$ ). Note that in analysing extreme temperature indices every possible values of the Sen's slope derived from the bootstrapping are summarized in violin plots, which, basically, show the kernel density estimation of the underlying distribution. Finally, seasonal trends of Tx and Tn anomalies are displayed using linear regressions for the 1950-2012 period, and by adjusting a locally weighted nonparametric polynomial regression (LOESS) with appropriate degree of smoothing (i.e., span; Figures 2-9). This method, which allows us to discuss non-linear characteristics of the trend of extreme temperature and HWs, has already been successfully applied in climate 
analysis (Cleveland and Devlin, 1988). Different span have been used to account for the time series with different lengths. For instance, a span of approximately 0.58 has been used for the regional indices (spanning the period 1900-2012), while the span is equal to 1 for the local/station time series (spanning the period 1950-2012). Similar adjustments of the span have been used to compare observed and simulated trends by the CMIP5 models in Sect. 3.3.

In addition, the contribution of trends in daily Tx and Tn anomalies, which can be considered as climatic signals, to extreme temperatures and HWs, which, basically, refer to intraseasonal events, has been discussed. A statistical sensitive experiment is performed by repeating the extreme index calculations and monotonic trend analysis after subtracting the influence of non-linear trends (i.e., LOESS) in daily Tx and Tn anomalies using a generalized linear model.

\section{3. $\quad \underline{\text { Results }}$}

Annual and seasonal climatology over the 1951-1980 period, which is used as baseline period in Sects. 3.1 and 3.2, is displayed in Figure 1. The West African region is clearly characterized by a meridional large-scale temperature gradient between the northern and southern regions, partly driven by sea-surface temperature in the equatorial Atlantic (Figure 1). As an annual average, temperature maxima are located over the Sahara, while lowest temperatures aligned along the Guinea Coast (Figure 1). This pattern, however, mainly reflects spring (AMJ) and summer (JAS) months, in which this temperature gradient contributes to the development and northward displacement of the West-African Monsoon. In the Sahel, the hottest season occurs during the pre-monsoon months, i.e., in $\mathrm{AMJ}$ (up to $32^{\circ} \mathrm{C}$ at $15^{\circ} \mathrm{N}$ and $0^{\circ} \mathrm{E}$; Figure 1). This pattern is shifted southward in winter (or dry season; JFM); warm temperature are therefore identified over the Gulf of Guinea coastal region. Meanwhile, autumn months (OND) are cold throughout West Africa compared to the annual mean (Figure $1)$. 

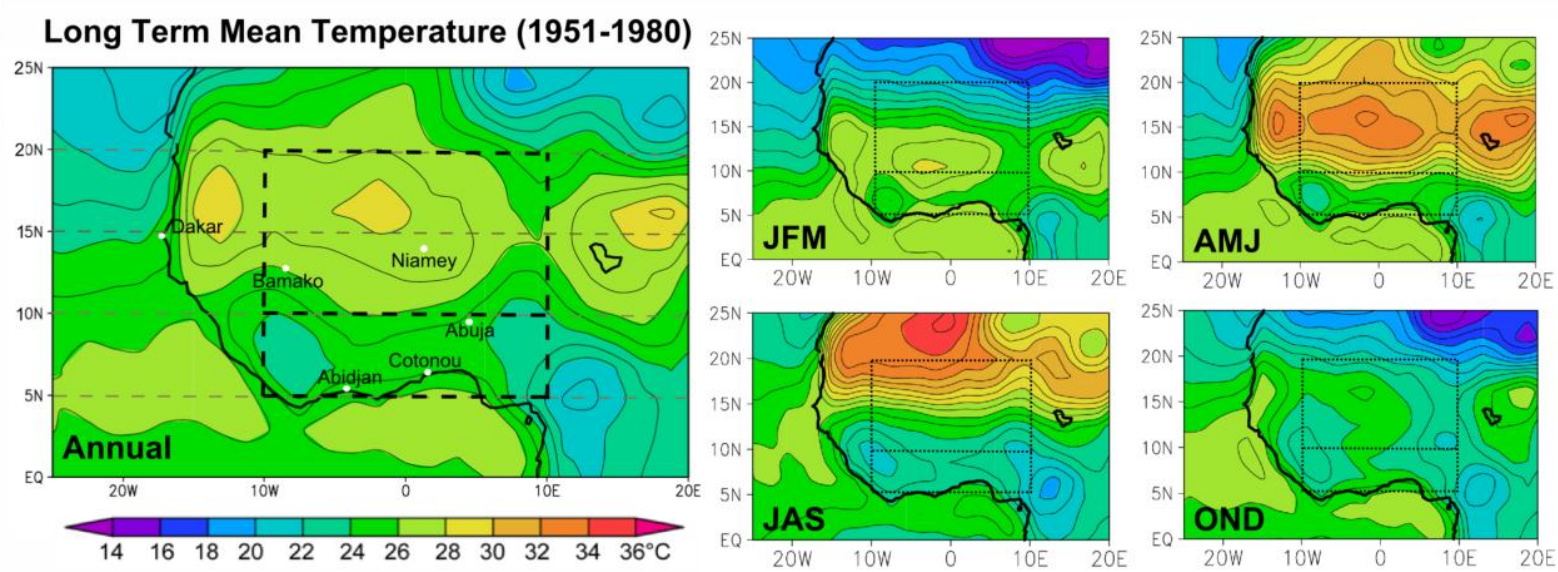

Figure 1. Mean air temperatures in West Africa between 1951 and 1980 (in ${ }^{\circ} \mathrm{C}$ ) using the NCEP/NCAR-1 reanalysis. The yearly mean is shown on the left; Seasonal means are shown on the right. The dotted rectangles correspond to the two regions studied: the Central Sahel $\left(10^{\circ}-20^{\circ} \mathrm{N} ; 10^{\circ} \mathrm{W}-10^{\circ} \mathrm{E}\right)$ and the Gulf of Guinea area $\left(4^{\circ}-10^{\circ} \mathrm{N} ; 10^{\circ} \mathrm{W}-10^{\circ} \mathrm{E}\right)$.

\subsection{Seasonal trends in diurnal and nocturnal daily temperature anomalies}

Seasonal time-evolution and trend of daily Tx and Tn anomalies is displayed for the Gulf Guinea coastal region in Figure 2, and for the Sahel in Figure 3. These daily Tx and Tn anomalies are analysed at the regional (via regionally aggregated indices) and local scales (via station data; Figures 2-3). Regionally aggregated indices have been computed over the Sahel $\left(10^{\circ}-20^{\circ} \mathrm{N} ; 10^{\circ} \mathrm{W}-10^{\circ} \mathrm{E}\right)$ and the Gulf of Guinea coastal regions $\left(4^{\circ}-10^{\circ} \mathrm{N} ; 10^{\circ} \mathrm{W}-10^{\circ} \mathrm{E}\right)$ using the BEST data set. As mentioned in Sect. 2.1, this data set provides Tx and Tn anomalies, which were calculated for each-grid point and each day with regards to the monthly average temperature of the 1951-1980 period. The same procedure has therefore been applied, at the local scale, to the weather stations. 

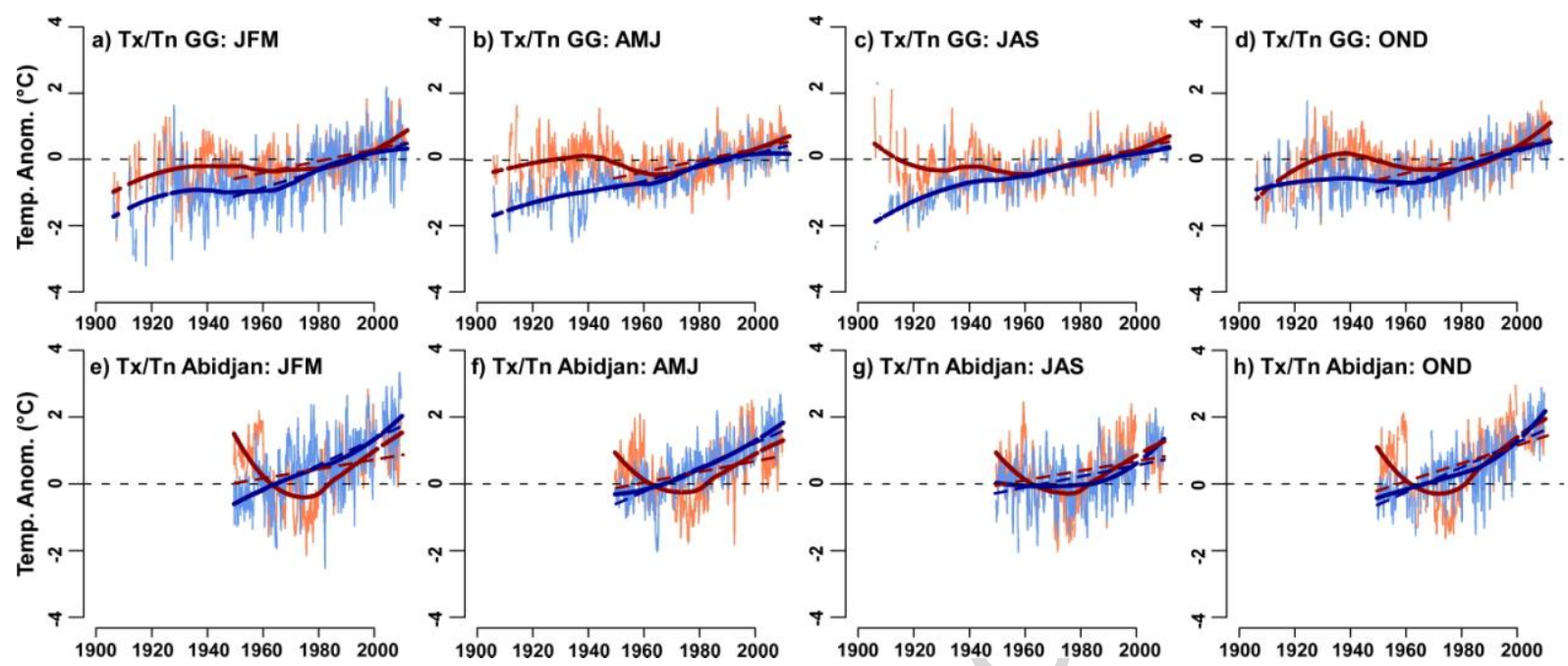

Figure 2. Seasonal time-evolution of daily Tx and Tn anomalies over the Gulf of Guinea coastal region (GG). (a-d) Daily Tx (light red) and Tn (light blue) anomalies of the GG regional index from BEST data set for each season (i.e., JFM, AMJ, JAS, OND) between 1900 and 2012. (e-h) as for (a-d) but using Abidjan station data between 1950 and 2012. Dashed bold lines indicate linear trends for the 1950-2012 period. Solid bold lines indicate locally weighted nonparametric polynomial regressions (LOESS) with adjusted degree of smoothing between regional and local anomalies (cf. Sect. 2.2). Daily Tx and Tn from BEST has been plotted using 30-days moving window for display purpose.

In JFM, at the regional scale, the Gulf of Guinea coastal regions display increasing trends in Tx and Tn from the beginning of the $20^{\text {th }}$ century, but these trends are non-linear (i.e., derivations to the linear regression trend lines; Figure 2a). These regional trends are more pronounced, and significant at $p=0.05$ (Figure 4a-b), over the second half of the $20^{\text {th }}$ century, especially in Tn (Figure 2a). The Tn warming is almost linear since 1950, while the Tx warming is accentuated over the post-1980s period (Figures 2a, 4a-b). This is clearer using Abidjan station data (Figure 2e). In JFM, the nocturnal/Tn warming trend is greater than the diurnal/Tx warming since the 1950, but this pattern tend to reverse over the post-1980s period (Figure 2a, e). 
During the same season, the Sahel regional index shows an almost linear warming trend in Tn during the $20^{\text {th }}$ century, while the Tx trend, which is highly non-linear, shows multidecadal fluctuations (Figure 3a). This is also evident between 1950 and 2012 using Niamey station data (Figure 3e). In JFM, at the regional and local scales, since 1950, a significant warming is identified in Tn, while there is no significant trend in Tx (Figure 4c-d). However, using the Sahel regional index and Niamey station data, the Tx trend is increasing significantly over the post-1980s period (Figures 3a, e, 4c). In JFM, during the post-1980s period, diurnal/Tx warming is greater than nocturnal/Tn warming over the Sahel (Figures. 3a, e, 4c-d).

In AMJ, over the Gulf of Guinea coastal regions, we note an almost linear warming in Tn during the $20^{\text {th }}$ century, while the Tx trend shows multidecadal fluctuations (Figure 2b). This difference between the trend in $\mathrm{Tx}$ and $\mathrm{Tn}$ is even more pronounced between 1950 and 2012 using Abidjan station data (Figure 2f). Since 1950, significant Tn warming trend is detected at the regional and local scales (Figure 4a-b). This is only significant at the local scale in Tx (Figure 4a-b). In AMJ, between 1950 and 2012, nocturnal/Tn warming is greater than diurnal/Tx warming over the Gulf of Guinea coastal regions. The Tx trend is however increasing significantly at the regional and local scales during the post-1980s period (Figures 2b-f, 4a).

Over the Sahel, in AMJ, at the regional and local scales, we note an almost strictly linear warming trend in Tn during the $20^{\text {th }}$ century (Figures $3 \mathrm{~b}, \mathrm{f}$ ). Warming Tx trend is only identified since 1960 (Figures 3b, f). Significant trends at $p=0.05$, which seems to be linear throughout the second half of the $20^{\text {th }}$ century, are therefore identified in Tx and Tn between 1950 and 2012 (Figure 4c-d). We nevertheless note non-significant trend in Niamey Tx and in the Sahel Tn regional index during the post-1980s period (Figure 4c-d). In AMJ, throughout the $20^{\text {th }}$ century, nocturnal/Tn warming is greater than diurnal/Tx warming over the Sahel (Figures 3b, f, 4c-d). 

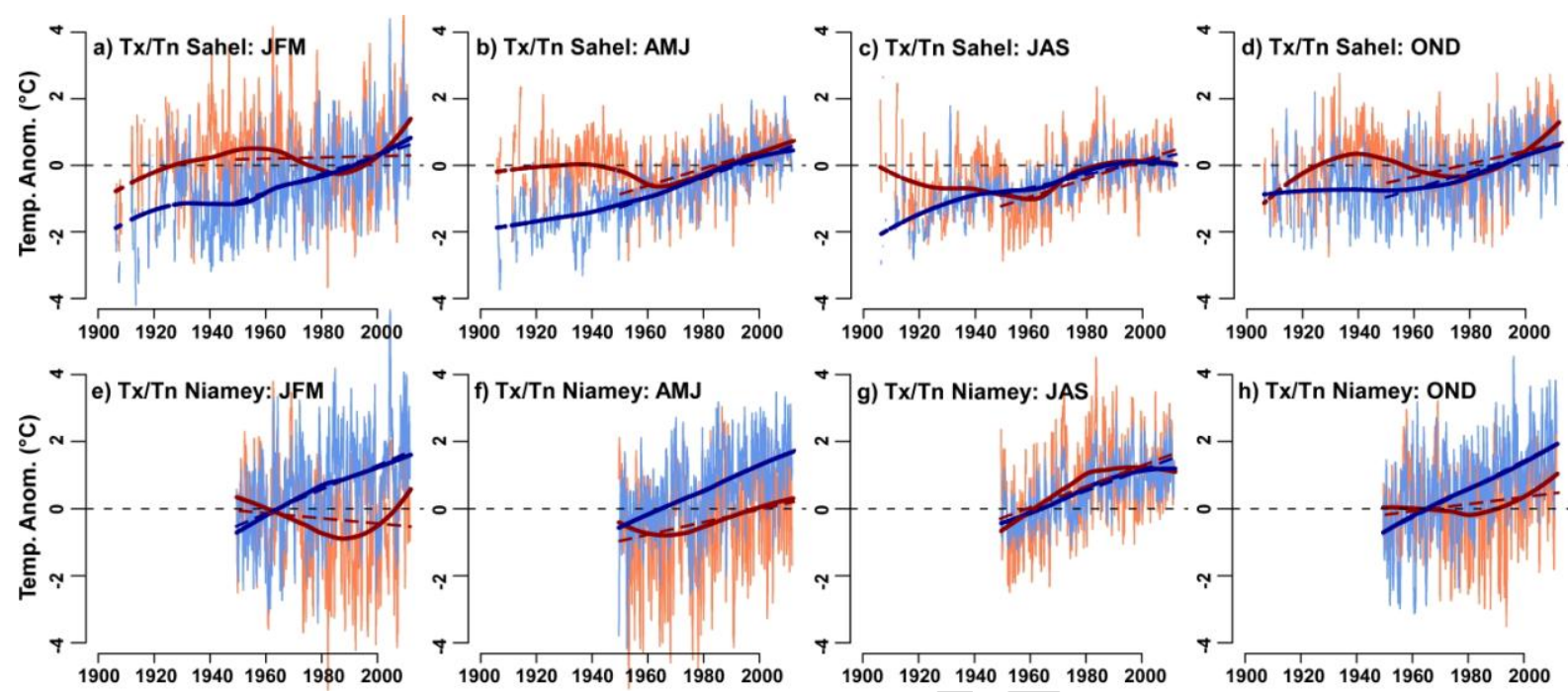

Figure 3. Seasonal time-evolution of daily Tx and Tn anomalies over the Sahel. (a-d) Daily Tx (light red) and Tn (light blue) anomalies of the Sahel regional index from BEST data set for each season (i.e., JFM, AMJ, JAS, OND) between 1900 and 2012. (e-h) as for (a-d) but using Niamey station data between 1950 and 2012. Dashed bold lines indicate linear trends for the 1950-2012 period. Solid bold lines indicate locally weighted nonparametric polynomial regressions (LOESS) with adjusted degree of smoothing between regional and local anomalies (cf. Sect. 2.2). Daily Tx and Tn from BEST has been plotted using 30-days moving window for display purpose.

In JAS, at the regional scale, the Gulf of Guinea coastal regions show an almost linear trend in Tn from the beginning of the $20^{\text {th }}$ century, while the Tx trend is warming almost linearly since 1960 (Figure 2c). However, using Abidjan station data, these warming trends in Tx and Tn do not seem to be linear between 1950 and 2012 (i.e., large deviations to the linear regression trend lines; Figure 2g). Between 1950 and 2012, we note significant Tn warming at the regional and local scales, while this is only identified at the regional scale in Tx (Figure. 4ab). In JAS, this warming is slightly more pronounced in diurnal/Tx than in nocturnal/Tn over the 1950-2012 period (Figure 4a-b). However, Tx are significantly rising at the regional and local scales over the post-1980s period, while this is only noted in Tn using Abidjan station data (Figures 2c, g, 4a-b). There is no significant trend in Tn over the post-1980s at the 
regional scale over the Gulf of Guinea coastal regions (Figure 4b). Nocturnal/Tn is therefore warming up earlier (throughout the $20^{\text {th }}$ century) than the diurnal/Tx trend (Figure $2 \mathrm{c}, \mathrm{g}, 4 \mathrm{a}-$ d). However, the Tx warming trend might be greater than Tn warming over the post-1980s period (Figure 2c, g, 4a-d).

In JAS, over the Sahel, the Tn trend is increasing non-linearly at the regional scale since the beginning of the $20^{\text {th }}$ century (Figures $3 \mathrm{c}$ ). The Tx Sahel warming is only identified since 1960 at the regional scale, but this trend is non-linear (Figure 3c). At the regional and local scales, Tx and Tn anomalies show significant trends at $p=0.05$ between 1950 and 2012 (Figure 4c-d). During that period, diurnal/Tx warming is greater than nocturnal/Tn warming in the Sahel (Figures 3c, g, 4c-d). However, these trends are substantially weakened after the 1970s (Figure 3c, g). There are therefore no significant trends in Tx and Tn (except using Niamey station data) over the post-1980s period (Figure 4c-d),

In OND, at the regional scale, the Gulf of Guinea coastal regions display warming trends in Tx and Tn over the $20^{\text {th }}$ century (Figure $2 \mathrm{~d}$ ). However, these trends are also not linear. For instance, the Tn regional warming trend is more pronounced since 1960 (Figures 2d, 4b). During that period, the Tn warming trend is almost linear using a regional index, but shows an intensification over the post-1980s period using Abidjan station data (Figure 2d). Between the 1950-2012 and 1980-2012 periods, linear trends are significant at $p=0.05$ (Figure 4b). The Tx warming trend, which is already significant between 1950 and 2012, is more pronounced over the post-1980s period at the regional and local scales (Figure 2d, h, 4a). In OND, nocturnal/Tn warming is therefore slightly greater than diurnal/Tx warming between 1950 and 2012, but it might not be verified over the post-1980s period (Figure 2c, g, 4a, b).

In OND, similar results are identified over the Sahel (Figures 3d, h). Non-linear warming trends are identified in Tx and Tn over the $20^{\text {th }}$ century (Figure $3 \mathrm{~d}$ ). At the regional and local 
scales, the Tn trend is more pronounced, and almost linear, during the second half of the $20^{\text {th }}$ century (Figure 3d, h). Since 1950, significant Tn warming trends at $p=0.05$, which slightly increase over the post-1980s period, are detected over the Sahel (Figure 4d). Significant Tx trends during the 1950-2012 period, which are highly non-linear, are much more pronounced over the post-1980s period (Figure 3d, h, 4c). In OND, over the Sahel, nocturnal/Tn warming is therefore greater than diurnal/Tx warming between 1950 and 2012. This pattern, however, tends to reverse over the post-1980s period.
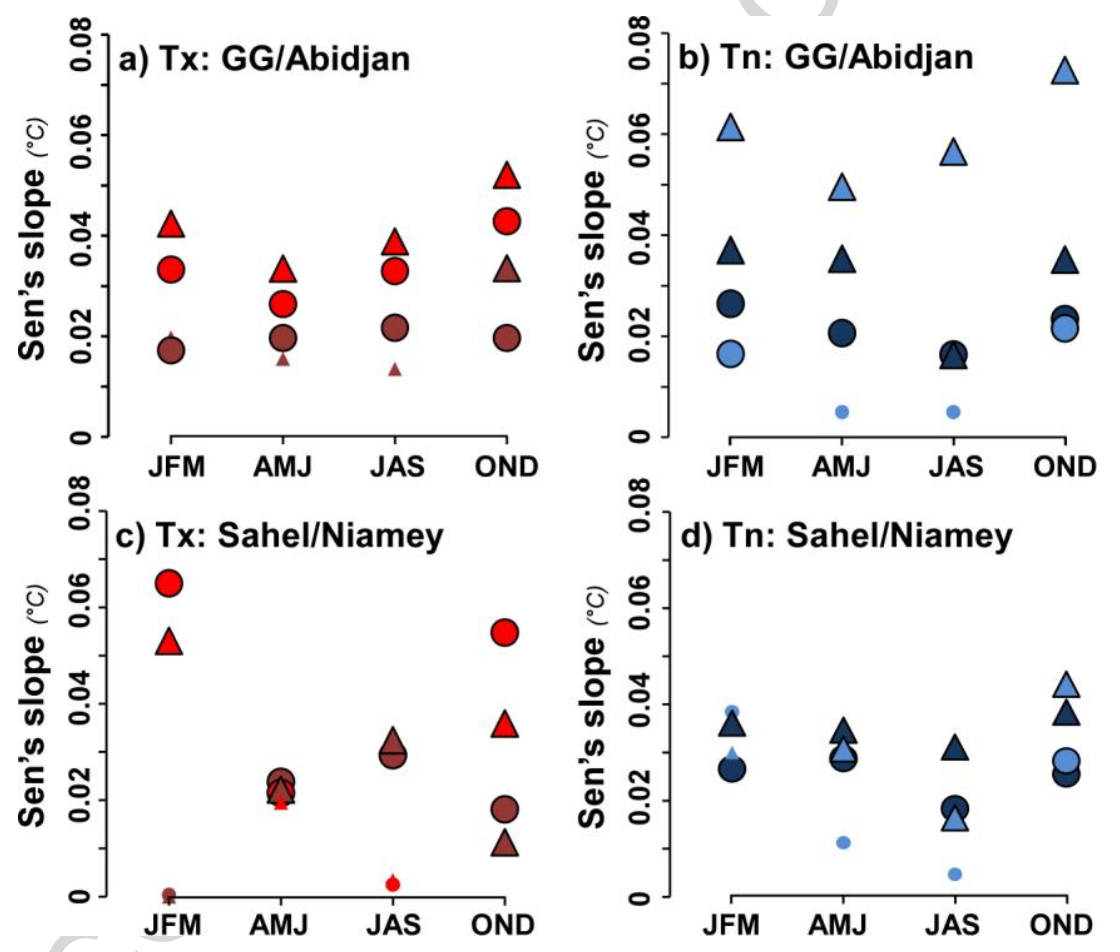

Figure 4. Seasonal trends of regional and local Tx and Tn over the Gulf of Guinea coastal region (GG) and the Sahel during the 1950-2012 (dark colours) and 1980-2012 (light colours) period. (a-b) Mann-Kendall Sen's slope estimations of Tx (red) and Tn (blue) using a GG regional index (circle) and Abidjan station data (triangle). (c-d) as for (a-b) but using a Sahel regional index and Niamey station data. Little circle and triangle indicate nonsignificant trends at $p=0.05$ with regards to a Mann-Kendall trend test accounting for serial correlations.

In summary, non-linear warming trends are identified in Tx and Tn anomalies over the Gulf of Guinea coastal regions and over the Sahel. Such non-linear trends are characterized, in 
particular, by an intensification of: i) nocturnal/Tn warming over the second half of the $20^{\text {th }}$ century; and ii) diurnal/Tx warming over the post-1980s. These results are therefore consistent with Fontaine et al. (2013), who found a warming in mean temperatures over the Sahel. However, in the present study, we show that, since 1980, there is no diurnal and nocturnal warming during the Sahel Monsoon season (i.e., JAS). In addition, we found nonlinear trends, which are likely to alter the daily temperature ranges. As reported at the global scale (Braganza et al., 2004), nocturnal/Tn warming is greater than diurnal/Tx warming since the mid- $20^{\text {th }}$ century. However, the opposite tends to occur over the post-1980s period. Diurnal/Tx warming is thus increasing for each season over the Gulf of Guinea coastal region, and for winter seasons (i.e., JFM and OND) over the Sahel.

\subsection{Trends in extreme temperature anomalies, and heatwave events.}

\subsubsection{Extreme warm days and nights}

Time-evolution and trend of the percentage of days of each season with daily Tx and Tn anomalies above the Tx90p and Tn90p, i.e., extreme warm days and nights, is displayed for the Gulf of Guinea coastal region in Figure 5, and for the Sahel in Figure 6.

In JFM, percentage of extreme warm days and nights increases since the 1960s, at the regional and local scales, over the Gulf of Guinea coastal regions (Figure 5a-b). Significant trends at $p=0.05$ are detected in more than $75 \%$ of bootstrap simulations in extreme warm days (except using Abidjan data) and extreme warm nights between 1950 and 2012 (Figure 5c). During this period, increasing trend of extreme warm nights is slightly greater than that of extreme warm days (Fig. 5c). However, these trends are not linear, in particular, using Abidjan station data (Figure 5a-c). Sen's slope values of both extreme warm days and nights, which are significant in most of the bootstrap simulations, are more pronounced over the post1980s period (Figure 5c). Increasing trend in extreme warm days also tends to be greater than extreme warm nights over the post-1980s period (Figure 5c). Furthermore, in JFM, time- 
evolution of trends in extreme warm days and nights over the Gulf of Guinea are strongly dependent on diurnal/Tx and nocturnal/Tn warming trends. There are no significant trends in extreme warm days and nights after subtracting the influence of diurnal and nocturnal warming trends (Figure 5c).

In the Sahel, in JFM, extreme warm nights increase regionally and locally over the second half of the $20^{\text {th }}$ century, while extreme warm days show multi-decadal fluctuations throughout the $20^{\text {th }}$ century (Figure 6a-b). Between 1950 and 2012, significant trends at $p=0.05$ are identified in extreme warm nights, but not in extreme warm days (Figure 6c). However, during the post-1980s period, percentage of extreme warm days increases substantially; this is significant between $50 \%$ and $75 \%$ of bootstrap simulations (Figure 6a-c). During that period, extreme warm nights slightly increase using a regional index, while there is no significant trend using Niamey station data (Figure 6a-c). Note, however, that the regional trend in extreme warm nights does not seem robust regarding the bootstrap results (less than $50 \%$ of simulations are significant at $p=0.05$; Figure 6c). In JFM, trends in Sahel extreme warm days and nights are strongly dependent to diurnal/Tx and nocturnal/Tn warming trends. There are no significant trends in Sahel extreme warm days and nights when subtracting the influence of diurnal and nocturnal warming trends (Figure 6c).
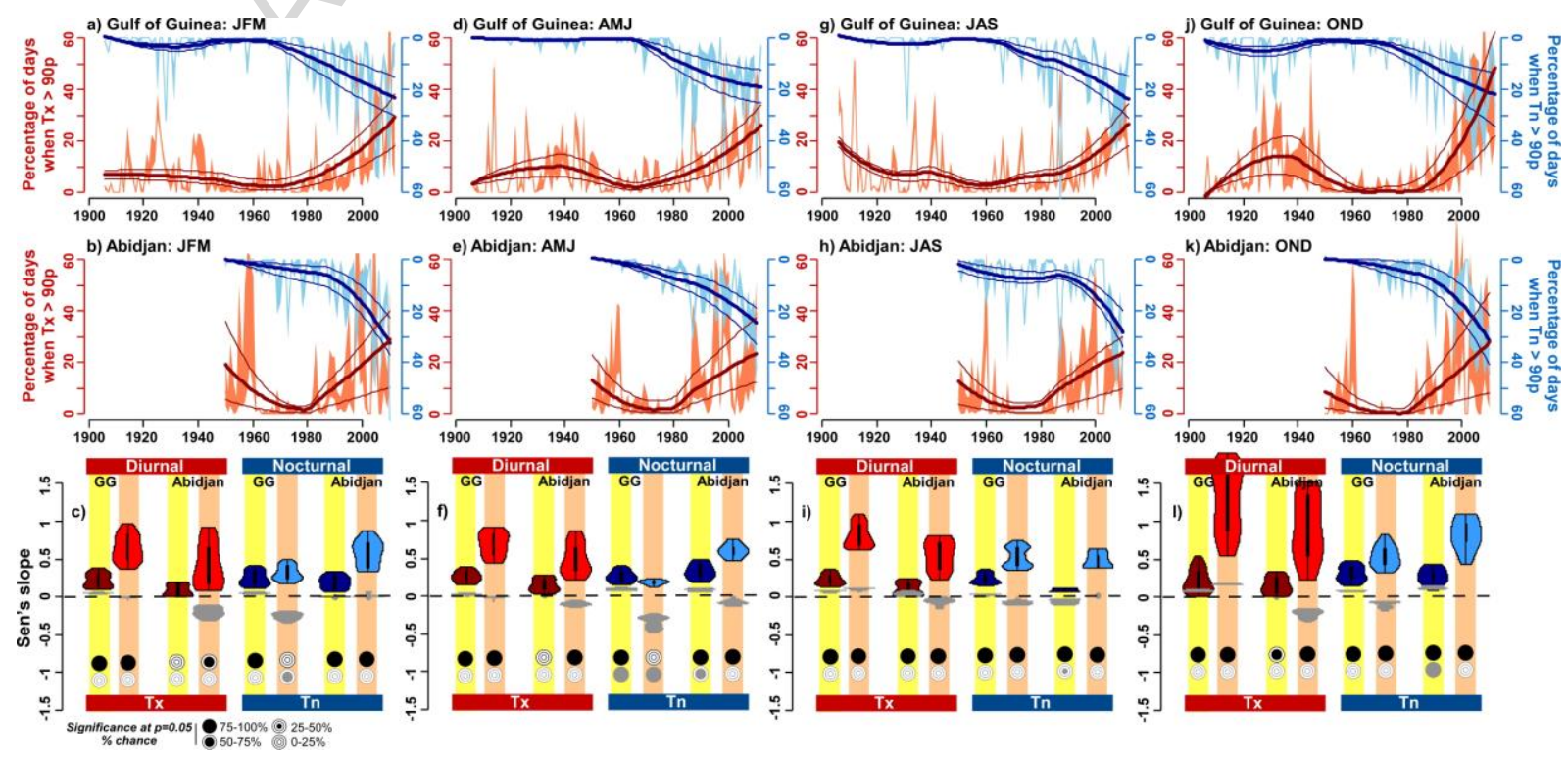
Figure 5. Percentage of days each season with daily Tx and Tn above the Tx90p and Tn90p, i.e., extreme warm days and nights, over the Gulf of Guinea coastal regions (GG). (Top panels) Seasonal percentage of extreme warm days (light red polygons) and nights (light blue polygons) between 1900 and 2012, as determined through every Tx90p and Tn90p values within the nonparametric bootstrap confidence intervals at $p=0.05$, using the GG regional index from BEST data set. (Middle panels) as for (top) but using Abidjan station data between 1950 and 2012. On the top and middle panels, solid bold (thin) lines indicate the average (maximal and minimal) trends, i.e., LOESS regressions, of bootstrap simulations. Note that the LOESS regressions have been adjusted degree of smoothing between regional and stationbased indices (cf. Sect. 2.2). (Bottom panels) Violin plot summarizing every possible Sen's slope values from the bootstrap simulations over the 1950-2012 (dark colours) and the 19802012 (light colours) periods. Grey violin plots indicate Sen's slope values using extreme warm day and nights calculated after subtracting linearly the influence of trends in daily Tx and Tn anomalies. Percentage of chance to obtain significant trends at $p=0.05$ has been assessed through a Mann-Kendall trend test accounting for serial correlations.
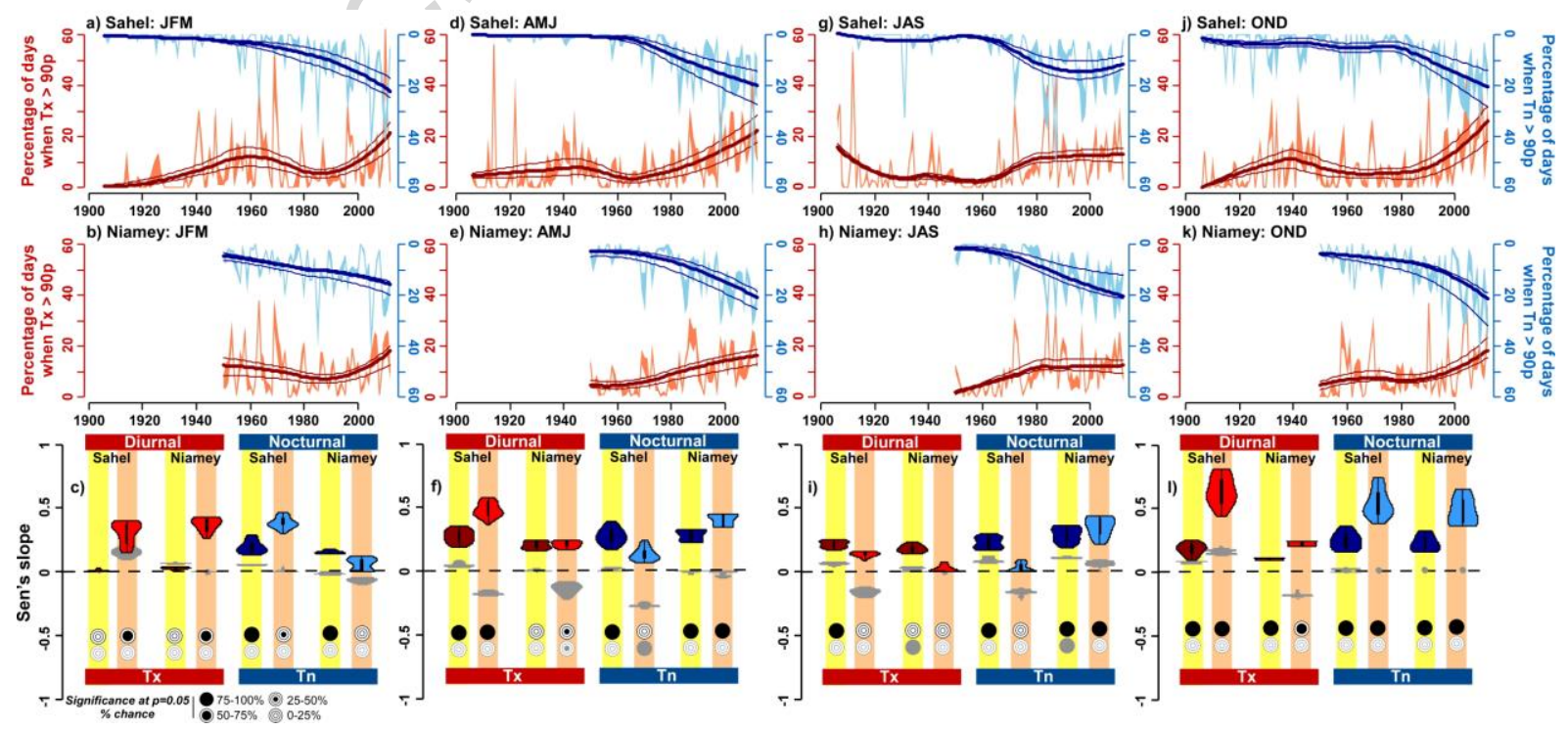

Figure 6. as for Figure 5 but using a Sahel regional index and Niamey station data. 
In AMJ, at regional and local scales, percentage of extreme warm nights increases during the second half of the $20^{\text {th }}$ century (in particular since 1960) over the Gulf of Guinea coastal regions (Figure 5d-e). Percentage of extreme warm nights over the Gulf of Guinea coastal regions displays multi-decadal fluctuations over the $20^{\text {th }}$ century, but we note an increasing trend since 1970/80 (Figure 5d-e). Between 1950 and 2012, significant trends in extreme warm nights and days (except using Abidjan station data) are identified in more than $75 \%$ of bootstrap simulations (Figure 5f). This increasing trend is, between 1950 and 2012, slightly more pronounced in extreme warm nights than in extreme warm days (Figure 5f). However, the percentage of extreme warm days is significantly rising over the post-1980s period (Figure 5d-f). During that period, increasing trend of extreme warm nights is less pronounced using the regional index, and much more pronounced using Abidjan station data (Figure 5d-f). Time-evolution of the trend in extreme warm days is strongly related to the diurnal/Tx warming trend over the Gulf of Guinea coastal regions. This is also true for the post-1980s trend of extreme warm nights (Figure 6f). However, between 1950 and 2012, significant increasing trends are still identified in extreme warm nights over the Gulf of Guinea coastal regions, even if we remove the influence of nocturnal/Tn warming trends (Figure 6f). The climatic warming trend, therefore, might not be the only driver of the post-1960s increase in extreme warm nights over the Gulf of Guinea coastal region.

Over the Sahel, in AMJ, percentage of extreme warm days and nights only increases since 1960 (Figure 6d-e). Between 1950 and 2012, significant trends in extreme warm night and days are therefore identified in more than $75 \%$ of bootstrap simulations (Figure $6 f$ ). Over the post-1980s period, contrasted patterns are observed using the Sahel regional index and Niamey station data. For instance, although increasing trend of extreme warm days are much more pronounced than between 1950 and 2012, there is no robust trends using Abidjan station data (i.e., less than $50 \%$ of trends of bootstrap simulations are significant). Furthermore, timeevolution of trends in Sahel extreme warm nights and days is strongly dependent on 
nocturnal/Tn and diurnal/Tx warming trends. In AMJ, there are no significant trends in Sahel extreme warm days and nights when subtracting the influence of diurnal and nocturnal warming trends (Figure 6f).

In JAS, over the Gulf of Guinea coastal regions, percentage of extreme warm days and nights increases over the second half of the $20^{\text {th }}$ century (Figure $5 \mathrm{~g}-\mathrm{h}$ ). At the regional and local scales, significant trends in extreme warm nights and days, which are of the same order of magnitude, are thus identified in more than $75 \%$ of bootstrap simulations between 1950 and 2012 (Figure 5i). However, these trends are highly non-linear, in particular using Abidjan station data (Figure 5g-h). Over the post-1980s period, increasing trends of extreme warm days and nights are both significantly more pronounced than during the 1950-2012 period (Figure 5g-i). During that period, increasing trend of extreme warm days tends to be greater than that of extreme warm nights (Figure 5i). Over the GG, time-evolution of trends in extreme warm days and nights is thus strongly related to nocturnal/Tn and diurnal/Tx warming trends. No significant trends in extreme warm days and nights over the Gulf of Guinea coastal regions are identified after subtracting the influence of diurnal and nocturnal warming trends (Figure 5i).

Over the Sahel, in JAS, percentage of extreme warm days and nights increase since 1960 at the regional and local scales (Figure 6g-h). Between 1950 and 2012, significant increasing trends, which are slightly more pronounced in extreme warm nights than in extreme warm days, are detected in more than $75 \%$ of bootstrap simulations (Figure 6i). However, these increasing trends are weakened over the post-1980s period (Figure 6g-h). Except in Niamey extreme warm nights, there is no significant trend in extreme warm night and days over the post-1980s (Figure 6i). In JAS, time-evolution of trends in Sahel extreme warm days and nights is thus strongly similar to that of nocturnal/Tn and diurnal/Tx anomalies. There are no 
significant trends in Sahel extreme warm days and nights after subtracting linearly the influence of diurnal and nocturnal warming trends (Figure 6c).

In OND, over the GG, percentage of extreme warm days and night increases regionally and locally during the second half of the $20^{\text {th }}$ century (Figure $5 \mathrm{j}-\mathrm{k}$ ). Significant trends at $p=0.05$ are identified in most of bootstrap simulations between 1950 and 2012 (Figure 51). These trends are, however, non-linear. Increasing trend in extreme warm nights is more pronounced over the post-1980s century, in particular using Abidjan station data (Figure 5j-1). Increasing trend in extreme warm days, which is particularly inhomogeneous regarding the bootstrap simulations, seems closely related to a very important rise over the post-1980s period (Figure 5j-1). Between 1950 and 2012, increase of extreme warm nights is slightly greater than that of extreme warm days, but this pattern tends to reverse over the post-1980s (Figure 5l). Furthermore, in OND, time-evolution of trends in Sahel extreme warm days and nights also runs parallel with nocturnal/Tn and diurnal/Tx warming trends. Except in Abidjan extreme warm nights, there are no significant trends in extreme warm days and nights over the GG after subtracting the influence of diurnal and nocturnal warming trends (Figure 51).

Over the Sahel, in OND, percentage of extreme warm days and nights increases non-linearly throughout the $20^{\text {th }}$ century (Figure 6j-k). Between 1950 and 2012, significant trends, which are slightly greater in extreme warm nights than in extreme warm days, are identified in more than $75 \%$ of bootstrap simulations (Figure 61). These increasing trends are, however, more pronounced over the post-1980s period in both extreme warm days and nights (Figure 6j-k). Over the post-1980s period, increase of extreme warm days tends to be greater than in extreme warm nights at least at the regional scale (Figure 6j-1). Furthermore, as for the other seasons, time-evolution of extreme warm days and nights is closely related to those of diurnal and nocturnal warming trends. In OND, there are no significant trends in Sahel extreme warm 
days and nights after subtracting linearly the influence of diurnal and nocturnal warming trends (Figure 61).

In summary, we note non-linear increases in extreme warm days and nights from the second half of the $20^{\text {th }}$ century over the Gulf of Guinea coastal regions and the Sahel. These trends are most of time more pronounced over the post-1980s periods, in particular for extreme warm days. While, between 1950 and 2012, increasing trend of extreme warm nights is greater than extreme warm days, this pattern tends to reverse during the post-1980s period. There is, however, no post-1980s increase of Sahel extreme warm days during the Monsoon season (i.e., JAS). Furthermore, increases in the percentage of extreme warm days and nights are principally driven by the climatic diurnal and nocturnal warming trends. This only partially explains the increase of extreme warm nights over the GG during the pre-Monsoon season (i.e., AMJ), where additional drivers should be investigated.

\subsubsection{Maximal and mean duration of diurnal and nocturnal warm spells}

We examine the annual maximal and mean durations of extreme warm days and warm nights over the two regions in Figure 7. Maximal (mean) durations of extreme temperature are defined as maximal (mean) consecutive days exceeding the Tx90p and Tn90p.
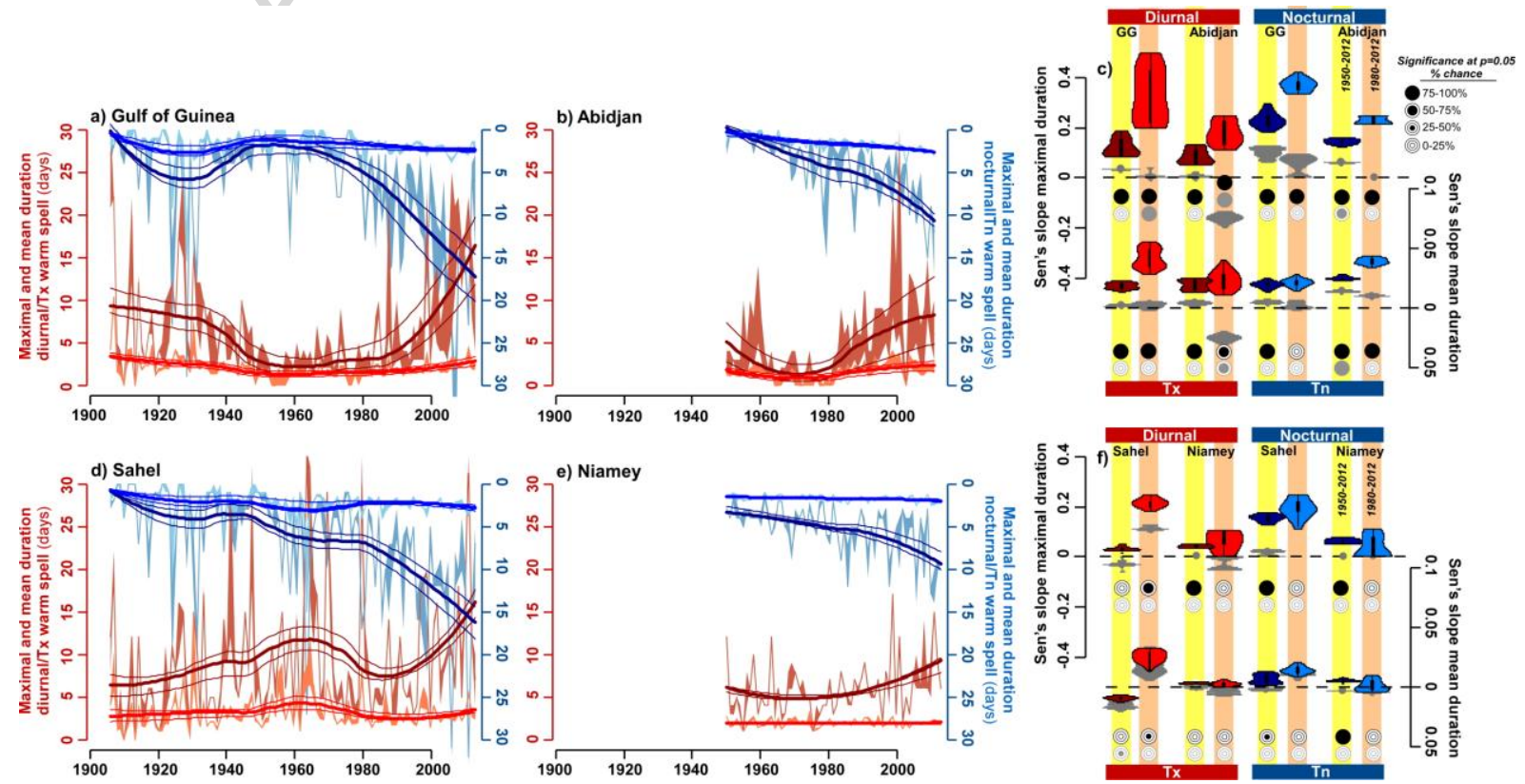
Figure 7. Maximal and mean durations of diurnal and nocturnal warm spells over the Gulf of Guinea coastal regions (GG) and the Sahel. (a-c) Time-evolution and trend of annual maximal (dark colours) and mean (light colours) duration of diurnal (red polygons) and nocturnal (blue polygons) warm spells, which are defined as maximal and mean consecutive days exceeding the Tx90p and the Tn90p, using the GG regional index and Abidjan station data. (d-f) as for (a-c) but using the Sahel regional index and Niamey station data. Note that polygons indicate warm spell durations for every Tx90p and Tn90p values within the nonparametric bootstrap confidence intervals at $p=0.05$. Solid bold (thin) lines indicate the average (maximal and minimal) trends, i.e., LOESS regressions, of bootstrap simulations. Note that the LOESS regressions have been adjusted degree of smoothing between regional and station-based indices (cf. Sect. 2.2). Violin plot summarizing every possible Sen's slope values from the bootstrap simulations over the 1950-2012 (dark colours) and the 1980-2012 (light colours) periods are displayed on the right hand panels. Grey violin plots indicate Sen's slope values using extreme warm day and nights calculated after subtracting linearly the influence of trends in daily Tx and Tn anomalies. Percentage of chance to obtain significant trends at $p=$ 0.05 has been assessed through a Mann-Kendall trend test accounting for serial correlations.

Over the Gulf of Guinea coastal regions, maximal and mean duration of diurnal and nocturnal warm spells show, at the regional scale, multidecadal fluctuations over the $20^{\text {th }}$ century (Figure 7a). At the regional and local scales, non-linear increasing trends are identified since 1950 in maximal and mean duration of nocturnal and diurnal warm spells (Figure 7a-b). Between 1950 and 2012, these trends are significant in more than $75 \%$ of bootstrap simulations (Figure 7c). These trends become more marked over the post-1980s period, in particular for the maximal duration of warm spells (Figure 7a-c). However, during these two periods, maximal and mean duration of diurnal warm spells are greater than that of diurnal warm spells (except at the regional scale for the mean duration of nocturnal warm spells; Figure 7c). Furthermore, over the GG, time-evolution of maximal and mean duration of 
diurnal and nocturnal warm spells are closely related to those of diurnal and nocturnal warming trends. Except for warm spell durations in Abidjan, which could highlight local inhomogeneities, there is no significant increase of warm spell durations after subtracting the influence of diurnal and nocturnal warming trends (Figure 7c).

In the Sahel, at the regional scale, maximal duration of diurnal and nocturnal warm spells increase non-linearly throughout the $20^{\text {th }}$ century, while mean duration of diurnal and nocturnal warm spells show little change (Figure 7d). This is also evident between 1950 and 2012 using Niamey station data (Figure 7e). Between 1950 and 2012, increasing trends in the maximal duration of nocturnal warm spells are detected in more than $75 \%$ of bootstrap simulations (Figure 7f). Although this is not verified using a regional index, which display large multidecadal fluctuations, maximal duration of diurnal warm spells also shows a significant increase between 1950 and 2012 (Figure 7d-f). At the regional scale, such a significant increase of maximal duration of diurnal warm spells is only identified between $50 \%$ and $75 \%$ of bootstrap simulations over the post-1980s period (Figure 7f). However, increasing duration of diurnal (in Niamey) and nocturnal warm spells over the post-1980s, which is evident through LOESS regressions, is not significant regarding a modified MannKendall test accounting for serial correlation (Figure 7d-f). At the same time, most of the time, there are no robust significant changes in the mean duration of diurnal and nocturnal warm spells (less than $50 \%$ of bootstrap simulations show significant trends; Figure $7 \mathrm{f}$ ). Furthermore, changes in the durations of Sahel diurnal and nocturnal warm spells are strictly related to diurnal and nocturnal warming trends. There is no significant increase of warm spell durations after subtracting the influence of diurnal and nocturnal warming trends (Figure 7c).

In summary, maximal and mean duration of diurnal and nocturnal warm spells has increase over the Gulf of Guinea coastal regions, in particular, over the second half of the $20^{\text {th }}$ century. Only maximal duration of diurnal and nocturnal warm spells shows an increasing trend over 
that period in the Sahel; this increase is, however, statistically quite questionable in the over the post-1980s period. We note that such increasing trends are primarily driven by the climatic diurnal and nocturnal warming trends.

\subsubsection{Annual number of diurnal and nocturnal heat waves.}

Time-evolution of annual number of diurnal and nocturnal HWs over the $20^{\text {th }}$ century is examined in Figure 8 for the two regions. As mentioned in Section 2.2., the annual number of diurnal and nocturnal HWs is defined as annual count of spells with at least $n$ consecutive days when Tx and Tn anomalies exceed the Tx90p and Tn90p. The number of consecutive days $n$, which is required to define HWs, is however very sensitive to the studied region, and this has never been discuss in the West-African context. Thus, in the present study, the annual number of diurnal and nocturnal HWs has been investigated for $3 \leq n \leq 8$ consecutive days.
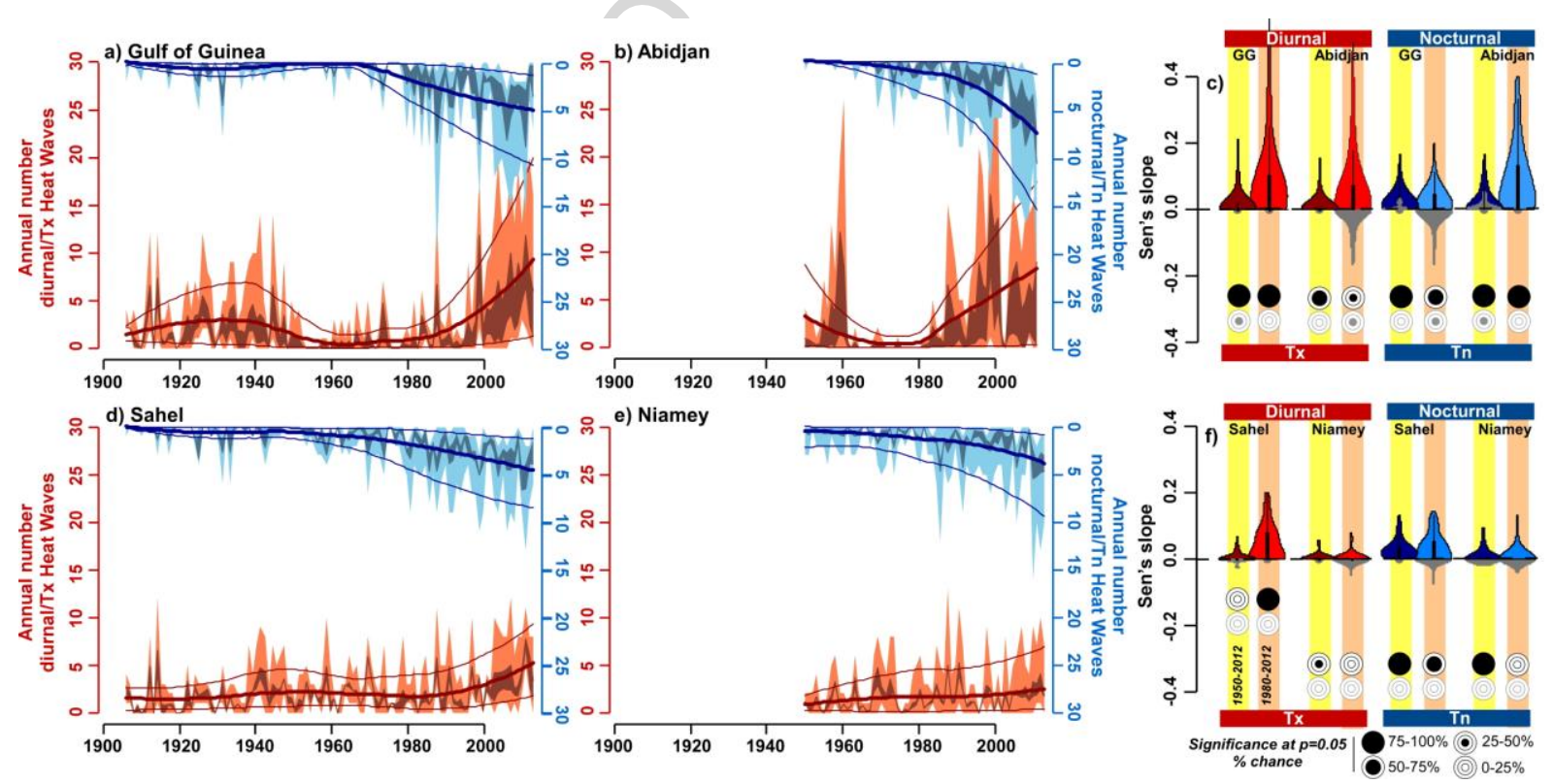

Figure 8. Annual number of diurnal and nocturnal heat waves over the Gulf of Guinea coastal regions (GG) and the Sahel. (a-c) Time-evolution and trend of annual number of diurnal (red) and nocturnal HWs (blue), which are defined as annual count of spells with at least $3<n<8$ consecutive days when Tx and Tn anomalies exceed the Tx90p and Tn90p, using the GG regional index and Abidjan station data. (d-f) as for (a-c) but using the Sahel regional index and Niamey station data. Dark polygons indicate number of HWs for every Tx90p and Tn90p 
values within the nonparametric bootstrap confidence intervals at $p=0.05$. Light polygons indicate number of HWs for every definition of $n$. Solid bold (thin) lines indicate the average (maximal and minimal) trends, i.e., LOESS regressions, of bootstrap simulations. Note that the LOESS regressions have been adjusted degree of smoothing between regional and stationbased indices (cf. Sect. 2.2). Violin plot summarizing every possible Sen's slope values over the 1950-2012 (dark colours) and the 1980-2012 (light colours) periods are displayed on the right hand panels. Grey violin plots indicate Sen's slope values using extreme warm day and nights calculated after subtracting linearly the influence of trends in daily $\mathrm{Tx}$ and $\mathrm{Tn}$ anomalies. Percentage of chance to obtain significant trends at $p=0.05$ has been assessed through a Mann-Kendall trend test accounting for serial correlations.

Over the Gulf of Guinea coastal regions, annual number of diurnal and nocturnal HWs has non-linearly increased, in particular over the second half of the $20^{\text {th }}$ century (Figure 8a-b). Between 1950 and 2012, significant trends are identified in more than $75 \%$ of HWs definitions (i.e., bootstrap simulations of Tx90p and Tn90p, as well as definition of $n$; Figure 8c). We note that trend in the number of nocturnal HWs tend to be slightly greater than that of diurnal HWs between 1950 and 2012 (Figure 8c). However, these trends are both increasing over the post-1980s period (Figure 8a-c). During that period, increasing trends in number of diurnal HWs tend to be greater than that of nocturnal HWs (Figure 8c). We also note that trends in the number of HWs are much more pronounced using $n=3$ than using $n=8$, which shows very little change (Figure 8a-c). Furthermore, over the Gulf of Guinea coastal regions, time-evolution of diurnal and nocturnal HW occurrences appears closely linked to the climatic diurnal and nocturnal warming trends. There is no significant increase of HWs after subtracting the influence of diurnal and nocturnal warming trends (Figure 8c). Between 25\% and $50 \%$ of HWs definitions nevertheless show an increase of nocturnal HWs over the GG, even after removing the influence of nocturnal climatic warming trends (Figure 8c). 
In the Sahel, at the regional scale, annual number of nocturnal HWs increases non-linearly over the 20th century, while diurnal HWs show very little change (Figure $8 \mathrm{~d}$ ). This pattern is also identified between 1950 and 2012 using Niamey station data (Figure 8e). Between 1950 and 2012, significant increasing trends in nocturnal HWs are detected in more than $75 \%$ of HW definitions, but not in diurnal HWs (Figure 8f). Number of nocturnal and diurnal HWs is both slightly increasing over the post-1980s (Figure 8d-f).

However, the post-1980s increase of diurnal and nocturnal HWs seems only robust using the Sahel regional index (more than $50 \%$ of definitions show significant trends; Figure $8 \mathrm{f}$ ). As for the Gulf of Guinea coastal regions, trends in the number of HWs are much more pronounced over the Sahel using $n=3$ than using $n=8$, which shows very little change (Figure 8d-f). Furthermore, time-evolution of diurnal and nocturnal heat wave occurrences over the Sahel is strictly related to the climatic diurnal and nocturnal warming trends. There is no significant increase of HWs after subtracting the influence of diurnal and nocturnal warming trends (Figure 8f).

In summary, annual number of diurnal and nocturnal HWs has increase over the Gulf of Guinea coastal regions over the second half of the $20^{\text {th }}$ century, and even more substantially over the post-1980s period. While, In Sahel, nocturnal HWs increase between 1950 and 2012, there is no consensus for robust changes in the number of diurnal HWs. We note that such increasing trends are primarily driven by the climatic diurnal and nocturnal warming trends. In addition, trends in the number of HWs are detected much more pronounced when using at least 3 consecutive days exceeding the $90^{\text {th }}$ percentile in defining HWs, while very little changes are detected using at least 8 consecutive days. In the absence of human impact data, HWs definitions using at least 5 consecutive days should therefore be a good compromise. Heat wave definition using at least 5 consecutive days exceeding a threshold has already been proposed by the Met-Office in the European context (Perry and Hollis, 2005; 
http://www.metoffice.gov.uk/learning/learn-about-the-weather/weather-

phenomena/heatwave).

\section{$\underline{3.3 \text { Validation of climate models and future projections }}$}

Observed trends in the percentage of extreme warm days and has been compared with those detected in CMIP5 model outputs (Figure 9; Table 1). Pre-processing of CMIP5 model outputs was required to restrict problems related to the spatial resolutions (Table 1). After the regridding, the comparison between simulated and observed trends has been performed using a grid-point centred on the stations. The historical trends are then compared with the projected trends over the $21^{\text {st }}$ century using two RCP scenarios: RCP 2.6 and RCP8.5, i.e. the most optimistic and pessimistic scenarios (Figure 9).
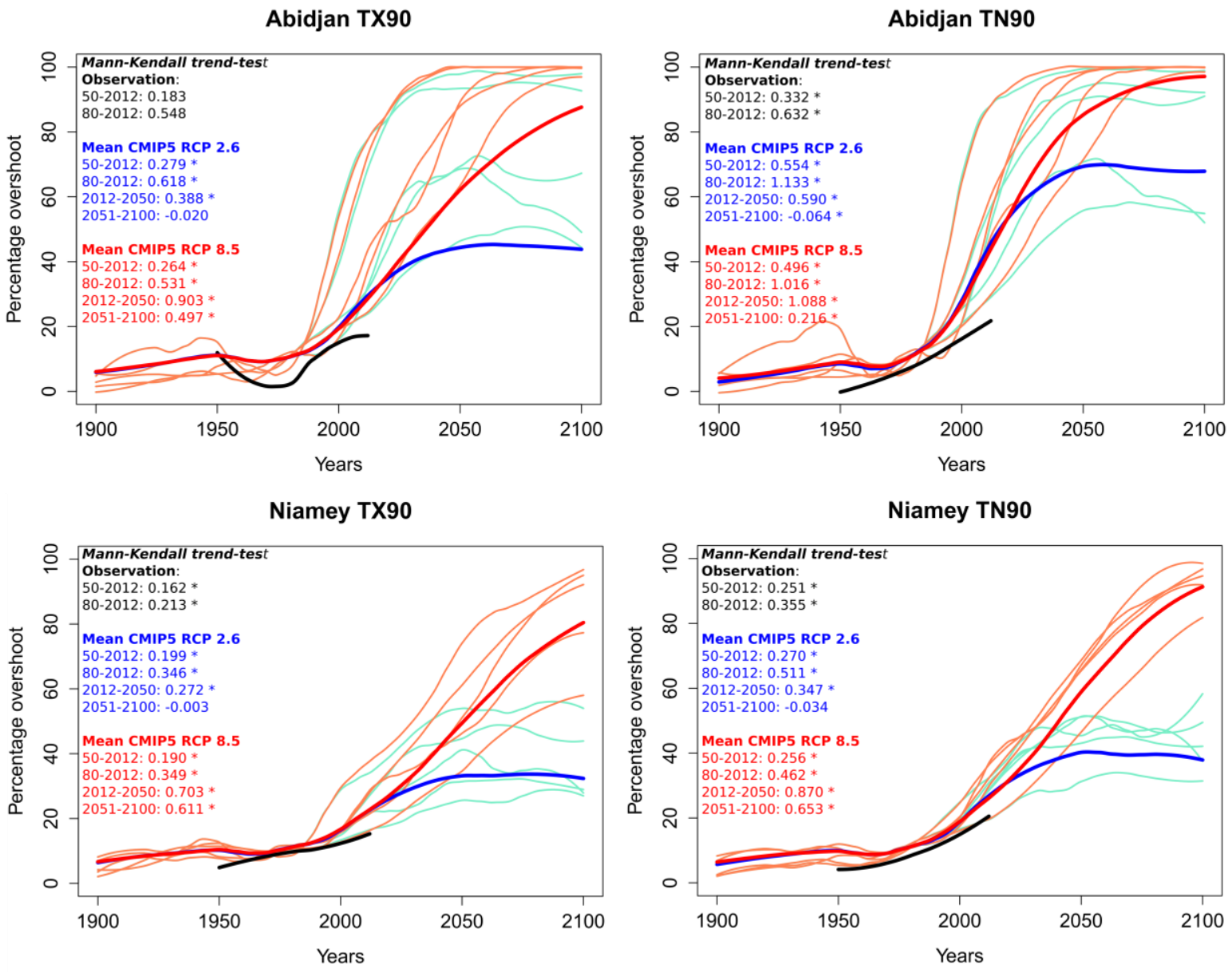

Figure 9. Observed (black lines) and simulated (coloured lines) trends in the percentage of days each year with daily Tn and Tx above the Tn90p and Tx90p over the two regions during 
the $20^{\text {th }}$ and $21^{\text {st }}$ centuries. Historical runs have been used between 1900 and 2012, while two RCP scenarios (i.e., RCP 2.6 and RCP 8.5) are selected to examine the future trends in WestAfrican extreme temperatures. Results from the individual models are indicated in turquoise and orange from the RCP 2.6 and RCP 8.5 scenarios, respectively. Red and blue bold lines show the results from the CMIP5 multi-model mean (MMM). Trends in West-African extreme temperatures are displayed by adjusting a LOESS smoothing for a span equal to the duration of observed time series (i.e., 60 years). The trend strength (Sen slope) and statistical significance (two-sided $p$-values) are evaluated using a modified Mann-Kendall trend test accounting for serial correlation. Asterisks indicate significant trends at $p=0.05$.

Between 1950 and 2010, observed and simulated trends are broadly similar over the two regions (Figure 9). Significant increasing trends at $p=0.05$, which seem more pronounced since the last quarter of the $20^{\text {th }}$ century, are identified in extreme warm days and nights (Figure 9). In the two regions, the trends of extreme warm nights are greater that in the percentage of extreme warm days. During the historical period, the simulated trends from the CMIP5 experiments are, however, always overestimated compared to the observations as determined by the Mann-Kendall's Sen Slope values (Figure 9). Simulated and observed trends are clearly diverging during the 1950s and the post-1990s. Although observed trends are almost linear between 1950 and 2012 (with the exception of the percentage of exceedance of Tx90p in Abidjan), simulated trends from the CMIP5 models display non-linear trends in the percentage of extreme warm days and nights, which are only rising since the 1970s (Figure 9).

In all scenarios, simulated rising trends are likely to be more and more pronounced over the two regions in the next 50 years. This is consistent with the results of the Mann-Kendall trend tests, which show much more pronounced trends (and significant at $p=0.05$ ) between 2012 and 2050 than during the historical period (Figure 9). As during the historical period, this 
exponential increase in the future trend of the West African extreme warm temperatures is more pronounced using the Tn90p than using the Tx90p except for the period 2051-2100 for Abidjan. The two scenarios only start to diverge after the first quarter of the $21^{\text {st }}$ century (Figure 9). During the second half of the $21^{\text {st }}$ century, a significant rising trend of extreme warm days and nights is likely to persist under the highest greenhouse gas emissions scenario (i.e., RCP 8.5), while this increasing trend should be stopped according to the lowest greenhouse gas emissions scenario (i.e., RCP 2.6). There are therefore no significant trends in the West African extreme temperatures over the second half of the $21^{\text {st }}$ century under the RCP2.6 scenario.

\section{Discussion and conclusion}

This study aims in filling the gap in understanding the relationship between trend and extreme in diurnal and nocturnal temperatures (Tx and Tn) over the Gulf of Guinea area and the Sahel, through seasonal fluctuations. Two data sets have been used to ensure the robustness of the results, and to examine the trends at the regional and local scales. To examine the timeevolution of extreme temperature anomalies and heat waves (HWs), we used the $90^{\text {th }}$ percentile of daily Tx and Tn anomalies (Tx90p and Tn90p), with respect to the 1951-1980 base period, as threshold. HWs have been defined as a period of consecutive days where conditions are excessively hotter than normal at that time of the year. There is therefore no universal definition of HWs, and many definitions could apply depending on the study region. In the present study, the annual number of diurnal and nocturnal HWs has been investigated for $3 \leq n \leq 8$ consecutive days, with $n$ the number of consecutive days.

At the regional and local scales, rising trends in $\mathrm{Tx}$ and $\mathrm{Tn}$, which appear more pronounced over the past 60 years, are identified over the two regions. The trends are characterized, in particular, by an intensification of: i) nocturnal/Tn warming over the second half of the $20^{\text {th }}$ century; and ii) diurnal/Tx warming over the post-1980s. These results are therefore consistent with Fontaine et al. (2013), who found a warming in mean temperatures over the 
Sahel. As reported over most locations over land (Easterling et al., 1997; Braganza et al., 2004; Wang et al., 2014), nocturnal/Tn warming is greater than diurnal/Tx warming since the mid- $20^{\text {th }}$ century, which results in a decrease in diurnal temperature range (DTR). However, the opposite tends occurred over the post-1980s period. Vose et al. (2005) show similar results; the decrease in DTR was attenuated in the early 1980s in many parts of the world.

According to Fontaine et al. (2013), hot spells over the Sahara and Sahel are linked to anomalous winds disturbing normal circulation in the upper and lower troposphere. Both the Harmattan and the subtropical airstream are thus weaker, resulting in a considerable increase in the amount of water vapour both at the surface and in the whole West African atmospheric column. It is shown here that this type of event should be defined differently in Sahel (10$\left.20^{\circ} \mathrm{N}\right)$ and Guinean $\left(5-10^{\circ} \mathrm{N}\right)$ latitudes. In this study we note non-linear increases in extreme warm days and nights from the second half of the $20^{\text {th }}$ century over the Gulf of Guinea coastal regions and the Sahel. These trends, in extremes temperatures, are most of time more pronounced over the post-1980s periods, in particular for extreme warm days. We note, between 1950 and 2012, increasing trend of extreme warm nights is greater than extreme warm days; this pattern tends to reverse during the post-1980s period. These increases in the percentage of extreme warm days and nights are principally driven by the climatic diurnal and nocturnal warming trends. However, in monsoon season (i.e., JAS) for the Sahel, there is no diurnal and nocturnal warming and no post-1890s increase in extreme warm days. As regards maximal and mean duration of diurnal and nocturnal warm spells, over the Gulf of Guinea coastal regions, there is an increasing, in particular, over the second half of the $20^{\text {th }}$ century. This is consistent with Trigo et al, (2005), who suggest that the substantial rise in Tn could lead to increase the risk linked to HWs. In Sahel there is only an increasing of maximal duration of diurnal and nocturnal warm spell. The most obvious and widely recognized mechanism from a meteorological point of view for the reduction of DTR is the increase of clouds, precipitation and soil moisture (Karl et al., 1993; Dai et al., 1999). Zhou et al. (2007) show that either a reduction in vegetation cover or a reduction in soil emissivity would reduce 
the DTR by increasing night-time's temperature through increased soil heating and reduce outgoing longwave radiation. According many authors (Dai et al., 2001; Stone and Weaver, 2003; Braganza et al., 2004; Christidis et al., 2005), these recent trends in extreme warm nights over the last century are large and unlikely due to natural variability alone. Other mechanisms, due to anthropogenic influence, such as greenhouse gases and aerosols, increases night-time downward longwave radiation (Zhou et al., 2007).

Finally annual number of diurnal and nocturnal HWs has increase over the Gulf of Guinea coastal regions, and more substantially over the post-1980s period, while, in Niamey, there is no consensus for robust changes in the number of diurnal HWs. In addition, trends in the number of HWs are detected much more pronounced when using at least 3 consecutive days exceeding the $90^{\text {th }}$ percentile in defining HWs, while very little changes are detected using at least 8 consecutive days. In the absence of human impact data, HWs definitions using at least 5 consecutive days should therefore be a good compromise.

However, these trends in extreme warm days are also identified in the CMIP5 "historical" simulations, which are not being susceptible to the sampling errors. Although these simulated trends are nevertheless always overestimated compared to the observed trends over the historical periods, those simulations display rising trends whatever the scenario, which are likely to be more and more pronounced over the two regions in the next 50 years. As described by Braganza et al. (2004), the overestimation of Tx warming in anthropogenic forced simulations may be due to poor representation of cloud changes over land. Observed increases in cloud cover since 1951 are not simulated by models forced with increasing greenhouse gases. Also (Dai et al., 2001; Stone and Weaver, 2003, 2002), showed that anthropogenic forcing by greenhouse gases and sulphate aerosols in Global Climate Models caused small $\left(0.2^{\circ} \mathrm{C}\right)$ decreases in global DTR over the 20th century.

Such warming could aggravate water and heat stress. In West Africa, however, heat stress can shorten the growing period, as observed by Diouf et al. (2001) in several countries in the Western Sahel (Senegal, Guinea Bissau, Mali). Food security is clearly threatened by climate 
change in the relatively short term (Lobell and Burke, 2008): with $1^{\circ} \mathrm{C}$ of warming by 2020 , roughly $65 \%$ of current maize growing areas in Africa will experience yield losses in optimal rain-fed conditions (assuming current management methods are maintained). Under drought conditions, $75 \%$ of areas can expect yield declines of at least 20\% (Lobell et al., 2011).

\section{Acknowledgements}

This work is a contribution to the activities of the Risques Hydrométéorologiques dans les Villes Africaines (RHYVA) [African City Hydro-meteorological Risks] network supported by the France's Ministry of Foreign and European Affairs (MAEE) through the Programme d'appui à la recherche en réseau en Afrique (PARRAF) [Support Programme for Research Networks in Africa]. It is also a contribution to ANR ACASIS (Sahelian heat-wave and health-impact warning system).

\section{References}

Alexander, L.V., Zhang, X., Peterson, T.C., Caesar, J., Gleason, B., Klein Tank, A.M.G., Haylock, M., Collins, D., Trewin, B., Rahimzadeh, F., Tagipour, A., Rupa Kumar, K., Revadekar, J., Griffiths, G., Vincent, L., Stephenson, D.B., Burn, J., Aguilar, E., Brunet, M., Taylor, M., New, M., Zhai, P., Rusticucci, M., Vazquez-Aguirre, J.L., 2006. Global observed changes in daily climate extremes of temperature and precipitation. J. Geophys. Res. 111. doi:10.1029/2005JD006290

Beniston, M., Diaz, H.F., 2004. The 2003 heat wave as an example of summers in a greenhouse climate? Observations and climate model simulations for Basel, Switzerland. Glob. Planet. Change 44, 73-81. doi:10.1016/j.gloplacha.2004.06.006

Bessemoulin, P., Bourdette, N., Courtier, P., Manach, J., 2004. La canicule d'août 2003 en France et en Europe. La Météorologie 8, 25. doi:10.4267/2042/36057 
Black, E., Blackburn, M., Harrison, G., Hoskins, B., Methven, J., 2004. Factors contributing to the summer 2003 European heatwave. Weather 59, 217-223. doi:10.1256/wea.74.04

Braganza, K., Karoly, D., Arblaster, J.M., 2004. Diurnal temperature range as an index of global climate change during the twentieth century. Geophys. Res. Lett. 31. doi:10.1029/2004GL019998

Christensen, J.H., Hewitson, B., Busuioc, A., Chen, A., Gao, X., Held, R., Jones, R., Kolli, R.K., Kwon, W.K., Laprise, R., Magana Rueda, V., Mearns, L., Menendez, C.G., Räisänen, J., Rinke, A., Sarr, A., Whetton, P., Arritt, R., Benestad, R., Beniston, M., Bromwich, D., Caya, D., Comiso, J., de Elia, R., Dethloff, K., 2007. Regional climate projections , Climate Change, 2007: The Physical Science Basis. Contribution of Working group I to the Fourth Assessment Report of the Intergovernmental Panel on Climate Change. Cambridge, pp. 847-940.

Christidis, N., Stott, P.A., Brown, S., Hegerl, G.C., Caesar, J., 2005. Detection of changes in temperature extremes during the second half of the 20th century. Geophys. Res. Lett. 32. doi:10.1029/2005GL023885

Cleveland, W.S., Devlin, S.J., 1988. Locally Weighted Regression: An Approach to Regression Analysis by Local Fitting. J. Am. Stat. Assoc. 83, 596-610. doi:10.1080/01621459.1988.10478639

Cowtan, K., Way, R.G., 2014. Coverage bias in the HadCRUT4 temperature series and its impact on recent temperature trends: Coverage Bias in the HadCRUT4 Temperature Series. Q. J. R. Meteorol. Soc. 140, 1935-1944. doi:10.1002/qj.2297

Dai, A., Trenberth, K.E., Karl, T.R., 1999. Effects of Clouds, Soil Moisture, Precipitation, and Water Vapor on Diurnal Temperature Range. J. Clim. 12, 2451-2473. doi:10.1175/1520-0442(1999)012<2451:EOCSMP>2.0.CO;2

Dai, A., Wigley, T.M.L., Boville, B.A., Kiehl, J.T., Buja, L.E., 2001. Climates of the Twentieth and Twenty-First Centuries Simulated by the NCAR Climate System 
Model. J. Clim. $\quad$ 14, 485-519. doi:10.1175/15200442(2001)014<0485:COTTAT>2.0.CO;2

Déqué, M, 2005. Coauthors Impact des changements anthropiques sur la fréquence des phénomènes extrêmes de vent, de température et de précipitations (IMFREX Final Report).

Diouf, M., Nonguierma, A., Amani, A., Royer, A., Some, B., 2001. Lutte contre la sécheresse au Sahel: résultats, acquis et perspectives au Centre régional AGRHYMET. Sci. Chang. PlanétairesSécheresse 11, 257-66.

Donat, M.G., Alexander, L.V., Yang, H., Durre, I., Vose, R., Dunn, R.J.H., Willett, K.M., Aguilar, E., Brunet, M., Caesar, J., Hewitson, B., Jack, C., Klein Tank, A.M.G., Kruger, A.C., Marengo, J., Peterson, T.C., Renom, M., Oria Rojas, C., Rusticucci, M., Salinger, J., Elrayah, A.S., Sekele, S.S., Srivastava, A.K., Trewin, B., Villarroel, C., Vincent, L.A., Zhai, P., Zhang, X., Kitching, S., 2013. Updated analyses of temperature and precipitation extreme indices since the beginning of the twentieth century: The HadEX2 dataset: HADEX2-GLOBAL GRIDDED CLIMATE EXTREMES. J. Geophys. Res. Atmospheres 118, 2098-2118. doi:10.1002/jgrd.50150

Easterling, D.R., Horton, B., Jones, P.D., Peterson, T.C., Karl, T.R., Parker, D.E., Salinger, M.J., Razuvayev, V., Plummer, N., Jamason, P., Folland, C.K., 1997. Maximum and Minimum Temperature Trends for the Globe. Science 277, 364-367. doi:10.1126/science. 277.5324 .364

ECOWAS-SWAC/OECD/CILS, 2008. Climate and Climate Change. The Atlas on Regional Integration in est Africa. Environment Series.

Fontaine, B., Janicot, S., Monerie, P.-A., 2013. Recent changes in air temperature, heat waves occurrences, and atmospheric circulation in Northern Africa. J. Geophys. Res. Atmospheres 118, 8536-8552. doi:10.1002/jgrd.50667

Goddess, C., 2005. STARDEX: Downscaling climate extremes. (STARDEX Final Report). Climatic Research Unit, University of East Anglia. 
Hamed, K.H., Ramachandra Rao, A., 1998. A modified Mann-Kendall trend test for autocorrelated data. J. Hydrol. 204, 182-196. doi:10.1016/S0022-1694(97)00125-X

Hulme, M., 2001. Climatic perspectives on Sahelian desiccation: 1973-1998. Glob. Environ. Change 11, 19-29. doi:10.1016/S0959-3780(00)00042-X

Kalnay, E., Kanamitsu, M., Kistler, R., Collins, W., Deaven, D., Gandin, L., Iredell, M., Saha, S., White, G., Woollen, J., Zhu, Y., Leetmaa, A., Reynolds, R., Chelliah, M., Ebisuzaki, W., Higgins, W., Janowiak, J., Mo, K.C., Ropelewski, C., Wang, J., Jenne, R., Joseph, D., 1996. The NCEP/NCAR 40-Year Reanalysis Project. Bull. Am. Meteorol. $\quad$ Soc. $\quad$ 77, 437-471. doi:10.1175/15200477(1996)077<0437:TNYRP>2.0.CO;2

Karl, T.R., Knight, R.W., Gallo, K.P., Peterson, T.C., Jones, P.D., Kukla, G., Plummer, N., Razuvayev, V., Lindseay, J., Charlson, R.J., 1993. A New Perspective on Recent Global Warming: Asymmetric Trends of Daily Maximum and Minimum Temperature. Bull. Am. Meteorol. Soc. 74, 1007-1023. doi:10.1175/15200477(1993)074<1007:ANPORG>2.0.CO;2

Lobell, D.B., Bänziger, M., Magorokosho, C., Vivek, B., 2011. Nonlinear heat effects on African maize as evidenced by historical yield trials. Nat. Clim. Change 1, 42-45. doi:10.1038/nclimate1043

Lobell, D.B., Burke, M.B., 2008. Why are agricultural impacts of climate change so uncertain? The importance of temperature relative to precipitation. Environ. Res. Lett. 3, 034007. doi:10.1088/1748-9326/3/3/034007

Meehl, G.A., 2004. More Intense, More Frequent, and Longer Lasting Heat Waves in the 21st Century. Science 305, 994-997. doi:10.1126/science.1098704

Pachauri, R.K., Reisinger, A., 2008. Bilan 2007 des changements climatiques: Rapport de synthese. GIEC.

Perkins, S.E., Alexander, L.V., 2013. On the Measurement of Heat Waves. J. Clim. 26, 45004517. doi:10.1175/JCLI-D-12-00383.1 
Perkins, S.E., Alexander, L.V., Nairn, J.R., 2012. Increasing frequency, intensity and duration of observed global heatwaves and warm spells: INCREASING OBSERVED GLOBAL HEATWAVES. Geophys. Res. Lett. 39, n/a-n/a. doi:10.1029/2012GL053361

Perry, M., Hollis, D., 2005. The generation of monthly gridded datasets for a range of climatic variables over the UK. Int. J. Climatol. 25, 1041-1054. doi:10.1002/joc.1161

Rohde, R., Muller, R., Jacobsen, R., Perlmutter, S., Mosher, S., 2013. Berkeley Earth Temperature Averaging Process. Geoinformatics Geostat. Overv. 01. doi:10.4172/2327-4581.1000103

Rome, S., Caniaux, G., Ringard, J., Dieppois, B., Diedhiou, A., 2015. Identification de tendances récentes et ruptures d'homogénéité des températures: exemple en Afrique de l'Ouest et sur le Golfe de Guinée. Presented at the 28ème colloque internationnal de 1'AIC, Liège, Belgium, pp. 591-596.

Santer, B.D., Taylor, K.E., Gleckler, P.J., Bonfils, C., Barnett, T.P., Pierce, D.W., Wigley, T.M.L., Mears, C., Wentz, F.J., Bruggemann, W., Gillett, N.P., Klein, S.A., Solomon, S., Stott, P.A., Wehner, M.F., 2009. Incorporating model quality information in climate change detection and attribution studies. Proc. Natl. Acad. Sci. 106, 1477814783. doi:10.1073/pnas.0901736106

Sen, P.K., 1968. Estimates of the Regression Coefficient Based on Kendall's Tau. J. Am. Stat. Assoc. 63, 1379-1389. doi:10.1080/01621459.1968.10480934

Stocker, T.F., Qin, D., Plattner, G.K., Alexander, L.V., Allen, S.K., Bindoff, N.L., ..., \& Xie, S.P., 2013. Technical summary. In Climate Change 2013: The Physical Science Basis. Contribution of Working Group I to the Fifth Assessment Report of the Intergovernmental Panel on Climate Change. Cambridge University Press.

Stone, D.A., Weaver, A.J., 2003. Factors contributing to diurnal temperature range trends in twentieth and twenty-first century simulations of the CCCma coupled model. Clim. Dyn. 20, 435-445. 
Stone, D.A., Weaver, A.J., 2002. Daily maximum and minimum temperature trends in a climate model. Geophys. Res. Lett. 29. doi:10.1029/2001GL014556

Taylor, K.E., Stouffer, R.J., Meehl, G.A., 2012. An Overview of CMIP5 and the Experiment Design. Bull. Am. Meteorol. Soc. 93, 485-498. doi:10.1175/BAMS-D-11-00094.1

Trigo, R.M., Garcia-Herrera, R., Diaz, J., Trigo, I.F., 2005. How exceptional was the early August 2003 heatwave in France? Geophys. Res. Lett. 32. doi:10.1029/2005GL022410

Vose, R.S., Easterling, D.R., Gleason, B., 2005. Maximum and minimum temperature trends for the globe: An update through 2004. Geophys. Res. Lett. 32.

Wang, F., Zhang, C., Peng, Y., Zhou, H., 2014. Diurnal temperature range variation and its causes in a semiarid region from 1957 to 2006: DIURNAL TEMPERATURE RANGE VARIATION AND CAUSES. Int. J. Climatol. 34, 343-354. doi:10.1002/joc.3690

Yue, S., Wang, C., 2004. The Mann-Kendall Test Modified by Effective Sample Size to Detect Trend in Serially Correlated Hydrological Series. Water Resour. Manag. 18, 201-218. doi:10.1023/B:WARM.0000043140.61082.60

Zhang, X., Hegerl, G., Zwiers, F.W., Kenyon, J., 2005. Avoiding Inhomogeneity in Percentile-Based Indices of Temperature Extremes. J. Clim. 18, 1641-1651. doi:10.1175/JCLI3366.1

Zhou, L., Dickinson, R.E., Tian, Y., Vose, R.S., Dai, Y., 2007. Impact of vegetation removal and soil aridation on diurnal temperature range in a semiarid region: Application to the Sahel. Proc. Natl. Acad. Sci. 104, 17937-17942. doi:10.1073/pnas.0700290104 


\section{Highlights}

Using different datasets, the rising of mean temperature is showed over West Africa

Over Guinea Coast region, there are both increases of Tmin and extreme warm nights

Over Sahel, we note increases of Tmax, Tmin and extreme warm days and nights

A decrease of the daily thermal range is observed over the last 60 years

The CMIP5 models display rising trends of warm spells whatever the scenario 